\title{
PLANTAS VASCULARES Y VEGETACIÓN DE LA PARTE ALTA DEL ARROYO AGUA FRÍA, MUNICIPIO DE MINATITLÁN, COLIMA, MÉXICO*
}

\author{
Eloy Padilla Velarde ${ }^{1}$, Ramón Cuevas Guzmán ${ }^{1}$ y Stephen D. $\mathrm{Koch}^{2}$ \\ ${ }^{1}$ Universidad de Guadalajara, Instituto Manantlán de Ecología y Conservación de la \\ Biodiversidad. Av. Independencia Nacional 151, \\ 48900 Autlán de Navarro, Jalisco, México. \\ elospave@yahoo.com.mx; rcuevas@cucsur.udg.mx \\ ${ }^{2}$ Colegio de Postgraduados, Instituto de Recursos Naturales, \\ Programa de Botánica, 56230 Montecillo, Estado de México, México. \\ sdkoch@colpos.colpos.mx
}

\section{RESUMEN}

Un inventario florístico de las plantas vasculares en la parte alta del arroyo Agua Fría, en el municipio de Minatitlán, Colima, México, permite registrar cinco divisiones, seis clases, 127 familias, 423 géneros, 716 especies y 36 unidades infraespecíficas de plantas vasculares. Doscientos sesenta y cinco especies constituyen nuevos registros para el estado de Colima. Las familias mejor representadas a nivel de género y especie son Asteraceae (49 y 92 respectivamente), Leguminosae (35 y 74) y Poaceae (19 y 34). Los géneros más diversificados son Eupatorium (15 spp.), Desmodium (12), Euphorbia (10), Ipomoea (8), Peperomia (8) y Quercus (8). Las hierbas son la forma de vida mas común con $46.77 \%$ de las especies. En el área existen 16 entidades específicas con alguna categoría de riesgo según la NOM-059-ECOL-2001. De éstas, ocho están amenazadas, seis bajo protección especial y dos en peligro de extinción. Se reconocen y describen cinco tipos de vegetación y un ecotono.

Palabras clave: Colima, inventario florístico, occidente de México, plantas vasculares.

\footnotetext{
* Trabajo presentado como requisito parcial para obtener el grado de maestro en ciencias en Botánica, en el Instituto de Recursos Naturales del Colegio de Postgraduados.
} 


\section{ABSTRACT}

A floristic inventory of vascular plants was carried out in the high parts of the Agua Fría stream in the Municipality of Minatitlán, Colima, Mexico. Five divisions, six classes, 127 families, 423 genera and 716 species, and 36 infraspecific taxa are registered. Two hundred and sixty five of the species reported in this research represent new reports for the State of Colima. The best genera and species rich families are the Asteraceae (49 and 92, respectively), Leguminosae (35 and 74) and Poaceae (19 and 34). Similarly the best species rich genera are Eupatorium (15), Desmodium (12), Euphorbia (10), Ipomoea (8), Peperomia (8) and Quercus (8). The life form with highest representation are herbs with $46.77 \%$ of the species. Within the area 16 vascular plant species belong to some kind of risk category according to NOM-059-ECOL-2001. Eight of them are threatened species, six under special protection and two in danger of extinction. Five vegetation types and one transitional type are recognized and characterized.

Key words: Colima, floristic inventory, vascular plants, western of Mexico.

\section{INTRODUCCIÓN}

Colima es uno de los estados de México que cuenta con poca información florística (Dávila y Sosa, 1994) y el conocimiento de sus comunidades vegetales es escaso. La información más importante sobre la flora del estado está publicada en la Flora Novo-Galiciana (McVaugh, 1974, 1983, 1984, 1985, 1987, 1989, 1992, 1993, 2001). Otros trabajos realizados para el estado o dentro de él, ponen de manifiesto la importancia de la región por su riqueza florística, la presencia de elementos endémicos, nuevos registros e inclusive especies nuevas para la ciencia (Sanders, 1992; Vázquez et al., 1995; Santana-Michel et al., 1992; Santana-Michel et al., 1998; Cuevas et al., 1998; Cuevas y Rzedowski, 1999; Padilla et al., 2005, 2006). Información sobre las comunidades vegetales del estado, se ha incluido en las descripciones generales de la vegetación de México y Nueva-Galicia (Miranda y Hernández, 1963; Rzedowski y McVaugh, 1966; Rzedowski, 1978; Pennington y Sarukhán, 1998). Sin embargo, pocos trabajos han abordado en forma particular su estudio (Sanders, 1992; Santana-Michel et al., 1992; Vázquez et al., 1995; Padilla et al., 2006), a pesar de que la entidad presenta una fuerte tasa de deforestación (Flores y Gerez, 1994). Este trabajo busca elaborar un catálogo de la flora vascular y conocer su estado de riesgo para una región del estado, así como describir y caracterizar sus comunidades vegetales. 


\section{MÉTODOS}

Área de estudio

La parte alta del arroyo de Agua Fría se delimita entre las coordenadas X 599959 a $602787\left(19^{\circ} 17^{\prime} 34^{\prime \prime}\right.$ y $\left.19^{\circ} 18^{\prime} 52^{\prime \prime} \mathrm{N}\right)$ y Y 2133516 a $2135921\left(104^{\circ} 01^{\prime} 17^{\prime \prime}\right.$ y $104^{\circ} 02^{\prime} 54^{\prime \prime}$ O), al noroeste del estado de Colima, en el municipio de Minatitlán. Pertenece al ejido del mismo nombre (Fig. 1). Se localiza aproximadamente a $9 \mathrm{~km}$ al suroeste de Minatitlán, que es la cabecera municipal. Tiene una superficie de 338 ha y una amplitud altitudinal que va de los 1040 a los $1930 \mathrm{~m}$, con una topografía muy accidentada. Se ubica dentro de la región hidrológica Costa de Jalisco, constituida por los ríos Purificación y Cihuatlán (Anónimo, 1981).

Fisiográficamente corresponde a la subprovincia Sierras de la Costa de Jalisco y Colima, que ocupa $62.51 \%$ de la superficie del estado de Colima y forma parte de la provincia Sierra Madre del Sur (Anónimo, 1981). El material parental está constituido por rocas ígneas extrusivas. El suelo predominante es el litosol, que es ácido y no apto para cultivos, asociado en el área al regosol, un tipo de suelo con poco o escaso desarrollo (Anónimo, 1981).

El clima dominante es el semicálido subhúmedo $(\mathrm{A}) \mathrm{C}\left(\mathrm{w}_{0}\right)(\mathrm{w}) \mathrm{a}$, de acuerdo con la clasificación Köppen modificada por García (1973). La temperatura media anual oscila entre $\operatorname{los} 20 \mathrm{y} \operatorname{los} 22^{\circ} \mathrm{C}$, mientras que en una pequeña proporción ubicada en la parte superior del área de estudio, va de los 18 a los $20^{\circ} \mathrm{C}$. La precipitación anual varía entre los 1000 y 1200 mm (Anónimo, 1981) (Fig. 2).

En la carta de uso potencial de suelo (Anónimo, 1977) se establece que el área sólo es apta para sostener vida silvestre y una práctica forestal muy moderada. Esto debido, principalmente, a las fuertes pendientes y al escaso desarrollo del suelo, que no permiten el establecimiento de agricultura de temporal ni de ganadería, con excepción de algunos espacios limitados, aprovechados para el pastoreo de bovinos.

De acuerdo con la información de la Comisión de Estudios del Territorio Nacional y la Secretaría de Programación y Presupuesto (Anónimo, 1975; Anónimo, 1981), la cobertura vegetal correspondería en aproximadamente $80 \%$ a bosque de encino y el resto estaría cubierto por vegetación secundaria.

Recolecta, proceso e identificación del material botánico

De septiembre del 2004 a agosto del 2005 se realizaron 11 excursiones a la zona de estudio. En cada visita se cubrió toda el área, y se realizaron recolectas en todas las variantes de tipos de vegetación y diferentes hábitats. Dos porciones extremas del arroyo se excluyeron del estudio, por cuestiones de seguridad física, 


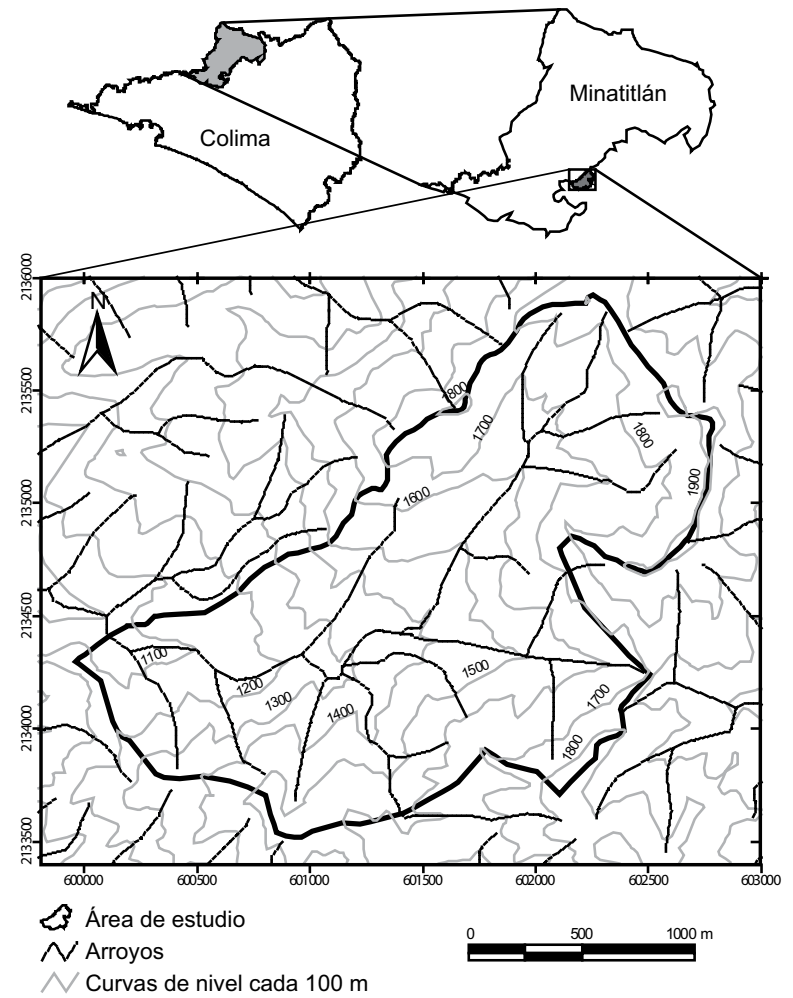

Fig. 1. Localización de la parte alta del arroyo de Agua Fría, municipio de Minatitlán, Colima.

ya que la abundancia de rocas y de víboras, así como su inaccesibilidad, nos llevó a tomar esta decisión. Los ejemplares reunidos se procesaron en el herbario ZEA del Instituto Manantlán de Ecología y Conservación de la Biodiversidad del Centro Universitario de la Costa Sur. El primer juego fue depositado en el Herbario CHAPA del Colegio de Postgraduados y duplicados en los Herbarios IEB y ZEA. Para la identificación del material se recurrió a claves y descripciones taxonómicas disponibles en floras regionales, monografías y revisiones taxonómicas, además de la consulta de ejemplares de los herbarios CHAPA, IBUG, IEB, IPN, MEXU y ZEA. Varios grupos taxonómicos fueron revisados por especialistas. La forma vital se determinó al realizar las colectas y con fundamento en la literatura especializada. La distribución de las especies por comunidades vegetales se definió mediante las observaciones de campo. La lista de los taxones que representan nuevos registros para el estado de 


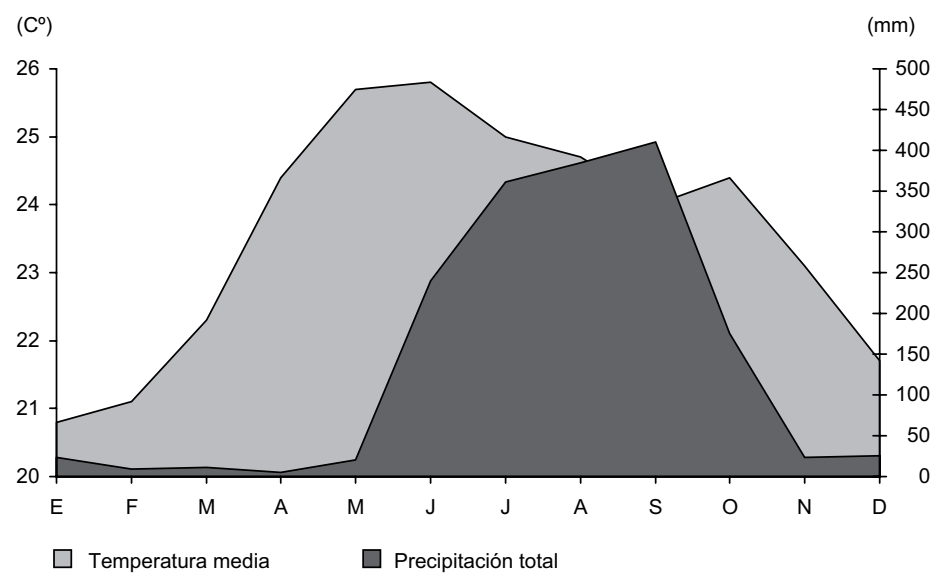

Fig. 2. Diagrama climático. Estación meteorológica de Minatitlán $\left(19^{\circ} 23^{\prime} \mathrm{N}, 1^{\circ} 4^{\circ} 03^{\prime} \mathrm{O}\right.$ y 730 m s.n.m.).

Colima (ver Apéndice) se obtuvo con base en la distribución geográfica registrada en las floras regionales, monografías y revisiones taxonómicas. La clasificación de las divisiones, clases y familias fue la de Cronquist (1981), excepto Leguminosae, la cual fue considerada como una sola familia (McVaugh, 1987; Takhtajan, 1997; Sousa y Delgado, 1998). Para las gimnospermas y pteridofitas se utilizó la clasificación empleada por McVaugh (1992).

El análisis del estado de riesgo de las especies se realizó con base en la lista de la Norma Oficial Mexicana NOM-059-ECOL-2001 (Anónimo, 2002).

La caracterización y descripción de los tipos de vegetación se hizo con apoyo de observaciones de campo, tomando en cuenta las especies dominantes y su fisonomía. Para la clasificación de las comunidades vegetales se utilizaron las propuestas de Rzedowski y McVaugh (1966) y Rzedowski (1978).

\section{RESULTADOS}

Florística

Con base en 960 números de recolecta y la revisión de cerca de 3,500 ejemplares, se registran cinco divisiones, seis clases, 127 familias, 423 géneros y 716 especies (Cuadro 1), así como 36 unidades infraespecíficas de plantas vasculares 
(Apéndice). Doscientos sesenta y cinco especies representan nuevos registros para el estado de Colima (Apéndice). 78.3\% de las especies pertenece a la clase Magnoliopsida, $14.8 \%$ a Liliopsida, $0.3 \%$ a Pinopsida y $6.6 \%$ a los helechos y plantas afines. El número promedio de especies por género (e/g) es de 1.7, el de géneros por familia (g/f) de 3.3 y el de especies por familia (e/f) de 5.6. Las familias con más géneros y especies son Asteraceae, Leguminosae y Poaceae, seguidas por las Rubiaceae a nivel de género, y por las Euphorbiaceae y Rubiaceae en términos de especies (Cuadro 2). Los géneros más diversificados son Eupatorium, Desmodium, Euphorbia, Ipomoea, Peperomia y Quercus (Cuadro 3).

Las hierbas son la forma de vida mejor representada con $46.77 \%$ de las especies; les siguen los árboles, con $22.66 \%$; los arbustos y subarbustos, con $20.03 \%$; y las trepadoras, con $10.54 \%$. De estas últimas $55 \%$ son de porte herbáceo y $45 \%$ son leñosas (bejucos o lianas). Las rupícolas constituyen 3.0\% y las epífitas 4.5\%, casi todas ellas hierbas. Se registraron seis especies de plantas parásitas y una saprófita (Cuadro 4).

Estado de riesgo de las especies

Se encontró que en el área existen 16 especies dentro de alguna categoría de riesgo, según la NOM-059-ECOL-2001 (Apéndice). De éstas, ocho están amenazadas, seis bajo protección especial y dos en peligro de extinción. De las 16, siete son árboles, cinco arbustos y cuatro hierbas. En bosque mesófilo de montaña se encuentran nueve, cinco crecen en bosque de encino, y dos habitan en el bosque tropical subcaducifolio.

Cuadro 1. Divisiones, clases, familias, géneros y especies de plantas vasculares registradas para la parte alta del arroyo de Agua Fría, municipio de Minatitlán, Colima.

\begin{tabular}{llccc}
\hline División & Clases & Familias & Géneros & Especies \\
\hline Psilotophyta & Psilotopsida & 1 & 1 & 1 \\
Lycopodiophyta & Lycopodiopsida & 2 & 2 & 4 \\
Filicophyta & Filicopsida & 8 & 25 & 42 \\
Pinophyta & Pinopsida & 1 & 1 & 2 \\
Magnoliophyta & Magnoliopsida & 103 & 334 & 561 \\
& Liliopsida & 12 & 60 & 106 \\
\hline Total & 6 & 127 & 423 & 716 \\
\hline
\end{tabular}


Cuadro 2. Familias más diversas a nivel de género y de especie en la parte alta del arroyo Agua Fría, municipio de Minatitlán, Colima.

\begin{tabular}{|c|c|c|c|}
\hline Familia & Núm. de géneros & Familia & Núm. de especies \\
\hline Asteraceae & 49 & Asteraceae & 92 \\
\hline Leguminosae & 35 & Leguminosae & 74 \\
\hline Poaceae & 19 & Poaceae & 34 \\
\hline Rubiaceae & 14 & Euphorbiaceae & 26 \\
\hline Acanthaceae & 11 & Rubiaceae & 25 \\
\hline Euphorbiaceae & 10 & Orchidaceae & 18 \\
\hline Orchidaceae & 12 & Solanaceae & 16 \\
\hline Adiantaceae & 8 & Aspleniaceae & 15 \\
\hline Malvaceae & 8 & Acanthaceae & 14 \\
\hline Scrophulariaceae & 8 & Lamiaceae & 14 \\
\hline Apocynaceae & 7 & Commelinaceae & 13 \\
\hline Cucurbitaceae & 7 & Adiantaceae & 12 \\
\hline Melastomataceae & 7 & Cyperaceae & 12 \\
\hline Aspleniaceae & 7 & Malvaceae & 12 \\
\hline \multirow[t]{3}{*}{ Total } & 200 & Piperaceae & 11 \\
\hline & & Scrophulariaceae & 11 \\
\hline & & Total & 399 \\
\hline
\end{tabular}

Cuadro 3. Géneros con mayor riqueza de especies.

\begin{tabular}{lc|lc}
\hline Género & Especies & Género & Especies \\
\hline Eupatorium & 15 & Salvia & 7 \\
Desmodium & 12 & Solanum & 7 \\
Euphorbia & 10 & Asplenium & 6 \\
Ipomoea & 8 & Crotalaria & 6 \\
Peperomia & 8 & Senna & 6 \\
Quercus & 8 & Stevia & 6 \\
Begonia & 7 & Total & 113 \\
Cuphea & 7 & & \\
\cline { 3 - 4 } & & &
\end{tabular}


Cuadro 4. Ubicación de las especies de plantas vasculares en diferentes categorías de formas de vida. *El total es mayor a las 716 especies del área, porque algunas presentan más de una forma vital, por lo que se cuentan en más de una ocasión.

\begin{tabular}{lrrrccr}
\hline & Árbol & $\begin{array}{c}\text { Arbusto y } \\
\text { subarbusto }\end{array}$ & Hierba & $\begin{array}{c}\text { Trepadora } \\
\text { herbácea }\end{array}$ & $\begin{array}{c}\text { Trepadora } \\
\text { leñosa }\end{array}$ & TOTAL \\
\hline Terrestre & 171 & 145 & 299 & 44 & 36 & 695 \\
Epífita & 1 & 2 & 31 & 0 & 0 & 34 \\
Rupícola & 0 & 0 & 23 & 0 & 0 & 23 \\
Parásita & 0 & 5 & 1 & 0 & 0 & 6 \\
Saprófita & 0 & 0 & 1 & 0 & 0 & 1 \\
\hline TOTAL & 172 & 152 & 355 & 44 & 36 & $759^{*}$ \\
\hline
\end{tabular}

En el área de estudio se registra 1.7\% de las especies consideradas en alguna categoría de riesgo para el país, según la NOM-059-ECOL-2001, así como 21.8\% de los árboles registrados para el estado dentro de alguna de estas categorías (Padilla et al., 2006).

Tipos de vegetación

En la parte alta del arroyo Agua Fría se reconocen y caracterizan cinco tipos de vegetación y un ecotono entre el bosque mesófilo de montaña y el bosque de encino (Fig. 3).

Bosque mesófilo de montaña (BMM). Es la vegetación dominante en el área de estudio y se estima que cubre $57.4 \%$ de la superficie. Sus límites altitudinales van de los $1400 \mathrm{a}$ los $1860 \mathrm{~m}$. En el estrato superior los árboles tienen alturas de 20-35 m. Las especies dominantes son Carpinus tropicalis, Clethra fragrans, Cornus disciflora, Ficus velutina, Fraxinus uhdei, Inga micheliana, Magnolia iltisiana, Prunus brachybotrya, P. cortapico, Quercus scytophylla, Q. uxoris, Rhamnus aff. sharpii, Symplococarpon purpusii, Symplocos novogaliciana y Zinowiewia concinna. En algunos sectores Carpinus tropicalis llega a formar pequeños bosquecillos, pero lo común en el área es que la dominancia sea compartida entre varias especies.

El estrato arbóreo inferior llega a medir hasta $15 \mathrm{~m}$ de altura, y entre los integrantes más comunes se encuentran Amyris rekoi, Calliandra laevis, Cestrum 


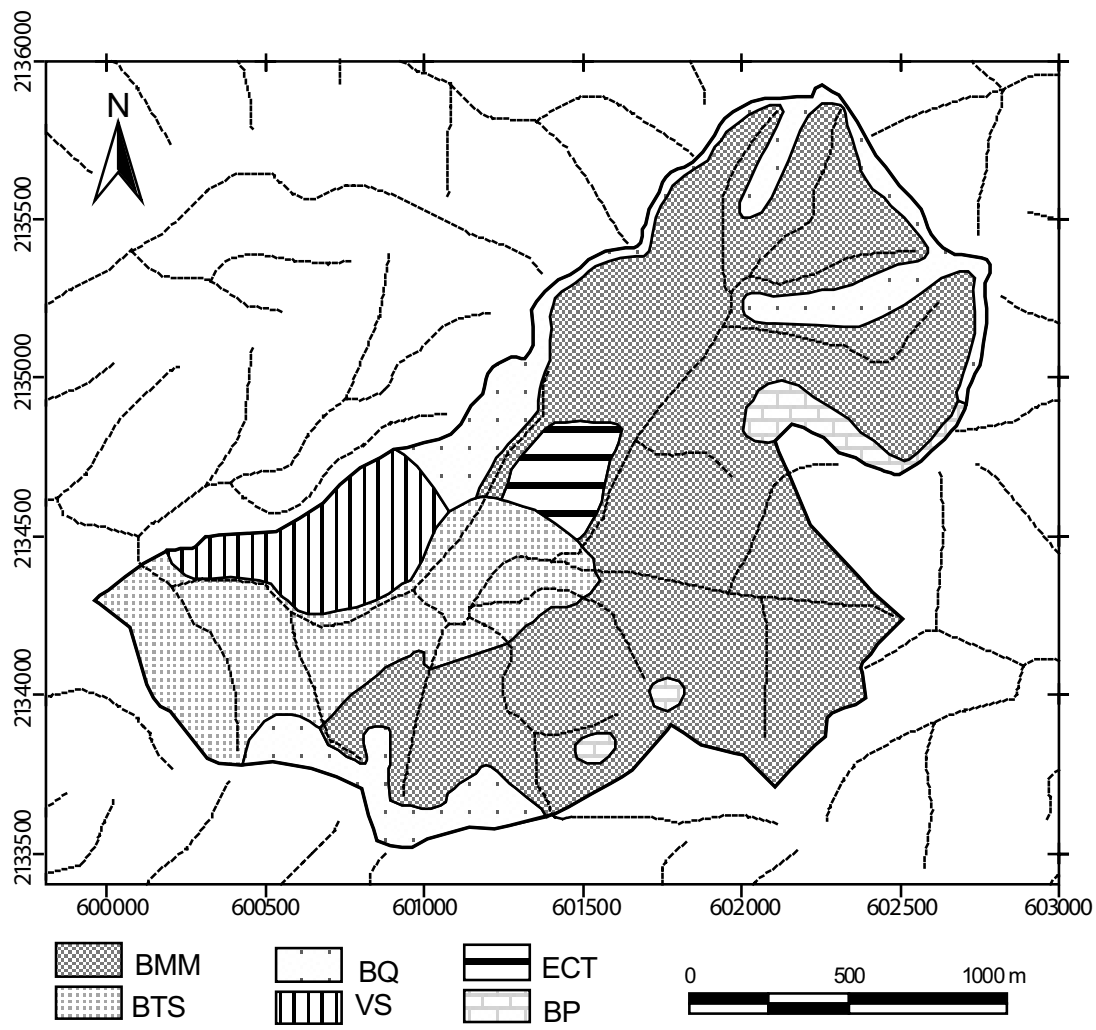

Fig. 3. Tipos de vegetación en la parte alta del arroyo de Agua Fría, municipio de Minatitlán, Colima. $\mathrm{BMM}=$ bosque mesófilo de montaña; $\mathrm{BTS}=$ bosque tropical subcaducifolio; $\mathrm{BQ}$ $=$ bosque de encino; $\mathrm{VS}=$ vegetación secundaria $; \mathrm{ECT}=$ ecotono entre bosque de encino $\mathrm{y}$ bosque mesófilo de montaña; y $\mathrm{BP}=$ bosque de pino.

nitidum, Chiococca pachyphylla, Citharexylum glabrum, C. hexangulare, Dendropanax arboreus, Euphorbia cotinifolia, Garrya longifolia, Guarea glabra, Inga colimana, Myrcianthes fragrans, Oreopanax echinops, Parathesis villosa, Quercus castanea, Q. excelsa, Rhamnus hintonii, Sebastiania hintonii, Solanum brevipedicellatum, Trema micrantha y Xylosma flexuosum. Por el borde de arroyos es común encontrar Boehmeria corallina, Hedyosmum mexicanum, Phenax mexicanus, Saurauia serrata, Trophis noraminervae y Turpinia occidentalis.

El estrato arbustivo, mide 2-4 m de altura, está compuesto principalmente por Bouvardia loeseneriana, Chamaedorea pochutlensis, Clidemia submontana, 
Desmodium madrense, Fuchsia encliandra, Pseudabutilon ellipticum, Psychotria horizontalis, Arachnothryx manantlanensis, Rumfordia floribunda, Salvia mexicana y Xylosma flexuosum.

Las especies trepadoras son abundantes sobre todo en los claros. De las de hábito herbáceo las más frecuentes son Bomarea hirtella, Cyclanthera jonesii, C. langaei, Schizocarpum dieterleae, Dioscorea plumifera, D. remotiflora, Cologania broussonetii, Phaseolus micranthus, P. vulgaris, Rhynchosia elisae, Vigna adenantha, Cissampelos pareira y Passiflora jorullensis. Las trepadoras leñosas más comunes son Canavalia hirsutissima, C. septentrionalis, Celastrus pringlei, Smilax moranensis, $S$. ornata y Vitis blancoi.

En esta comunidad vegetal se encuentran epífitas de las familias Orchidaceae, Bromeliaceae, Piperaceae, Aspleniaceae y Polypodiaceae. Las hierbas son escasas en el sotobosque, pero muy abundantes en claros ocasionados por disturbios o por la presencia de grandes rocas. Especies abundantes con comportamiento rupícola son Achimenes heterophylla, Elaphoglossum sartorii, Encyclia spatella, Nephrolepis undulada, Oxalis alpina, Pitcairnia karwinskyana, Sedum jaliscanum y Valeriana sorbifolia. Entre las hierbas no rupícolas las familias mejor representadas son Adiantaceae, Aspleniaceae, Asteraceae, Begoniaceae, Commelinaceae, Euphorbiaceae, Lamiaceae, Orchidaceae, Poaceae y Rubiaceae.

Bosque tropical subcaducifolio (BTS). Cubre $17.9 \%$ de la superficie, está restringido a la parte baja del área de estudio y encuentra su límite altitudinal superior a los $1480 \mathrm{~m}$. El estrato arbóreo superior varía de 15 a $25 \mathrm{~m}$ de altura y está dominado por Aphananthe monoica, Beilschmiedia manantlanensis, Calatola laevigata, Cecropia obtusifolia, Cedrela odorata, Cnidoscolus autlanensis, Coussapoa purpusii, Croton draco, Cupania dentata, Ficus glycicarpa, F. maxima, Lonchocarpus guatemalensis y Salix bonplandiana. En el arbóreo inferior, el cual oscila entre 5-15 m de altura, es común encontrar Annona reticulata, Bocconia arborea, Ceiba aesculifolia, Erythrina lanata, Lycianthes manantlanensis, Oreopanax echinops, Plumeria rubra, Pseudobombax ellipticum, Siparuna andina, Thouinidium decandrum, Trichilia americana y Verbesina oligantha. Por el borde de los arroyos es usual ver Sommera grandis y Urera corallina.

Entre los arbustos más abundantes destacan Boehmeria ulmifolia, Desmodium skinneri, Eupatorium monanthum, E. quadrangulare, Gonzalagunia panamensis, Lantana frutilla, Lycianthes manantlanensis, L. surotatensis, Malvaviscus arboreus, Pavonia pleuranthera, Periptera ctenotricha, Picramnia guerrerensis, 
Psychotria pubescens, Rhus terebinthifolia, Rogiera amoena, Arachnothryx jurgensenii, Senecio chapalensis, Solanum candidum, S. lanceifolium, Urera corallina y Zapoteca formosa.

La densidad de especies trepadoras puede llegar a ser considerable, sobre todo las de porte leñoso, entre las que destacan Callaeum malpighioides, Chusquea circinata, Drymonia serrulata, Hippocratea celastroides, Machaerium salvadorense, Mimosa albida, Philodendron anisotomum, Prestonia mexicana, Smilax moranensis, Solanum lanceifolium y Vitis blancoi. Entre las trepadoras herbáceas más comunes se encuentran Ipomoea purpurea, I. santillanii, Melothria pringlei, Sechium hintonii, Sicyos barbatus, Canavalia aff. septentrionalis, Centrosema plumieri, Phaseolus micranthus y Passiflora biflora.

El estrato herbáceo está por lo general ausente y la mayoría de las hierbas se encuentran confinadas a pequeños claros en el bosque o a las orillas de los arroyos. Las hierbas epífitas y rupícolas son escasas. Las familias más importantes por número de especies herbáceas son Asteraceae, Begoniaceae, Commelinaceae y Poaceae. Entre los helechos es evidente la presencia de representantes de Aspleniaceae y Adiantaceae.

Bosque de encino (BQ). Esta comunidad vegetal cubre aproximadamente $12.5 \%$ del área y tiene un intervalo altitudinal que va de los 1340 a los $1930 \mathrm{~m}$. Se encuentra sobre el parteaguas del arroyo, en las condiciones más secas y sobre suelos rocosos.

El estrato arbóreo se presenta en forma de parches de dos tipos. En uno de ellos la altura de los árboles varía de 10 a $20 \mathrm{~m}$ y en el otro de 5 a $10 \mathrm{~m}$. Al parecer la diferencia está dada por el sustrato en que se encuentran y la humedad. Los rodales con vegetación de menor talla se encuentran en suelos someros y pedregosos y sitios más expuestos a la desecación. En contraste, los de árboles más altos se localizan en sustrato más profundo y sitios más protegidos contra el viento, por lo que son más húmedos. La especie dominante en este último ambiente pertenece casi por completo a individuos de Quercus scytophylla. Bajo éstos se desarrolla un segundo estrato arbóreo entre cuyas especies resalta Ternstroemia lineata.

En la comunidad vegetal de árboles pequeños, la composición del estrato arbóreo es mucho más variada. Entre las especies más comunes se encuentran Acaciella angustissima, Alstonia pittieri, Arbutus xalapensis, Bernardia mexicana, Buddleja parviflora, Calliandra houstoniana, C. longipedicellata, Erythrina breviflora, Eysenhardtia platycarpa, Eugenia capuli, Lippia umbellata, Litsea glaucescens, Lysiloma acapulcense, Myrsine coriacea, Quercus elliptica, Q. iltisii, Q. rugosa, Q. 
sororia y Terntroemia lineata. El estrato arbustivo está bien desarrollado y entre los componentes más frecuentes se encuentran Calliandra longipedicellata, Crotalaria longirostrata, Erythrina breviflora, Eupatorium areolare, E. hebebotryum, E. ovaliflorum, E. lasioneuron, Eysenhardtia platycarpa, Galphimia langlassei, Hyptis oblongifolia, Lasianthaea fruticosa, Monnina xalapensis, Moussonia elegans, Russelia retrorsa, Salvia iodantha, Senecio roldana, Senna foetidissima, Solanum ferrugineum, Stevia subpubescens, Verbesina greenmanii, V. oncophora y Zapoteca tetragona. Las plantas herbáceas también son comunes en este tipo de vegetación. Las familias que destacan por su número de especies son Asteraceae, Cyperaceae, Leguminosae, Poaceae y Scrophulariaceae, además de helechos de la familia Adiantaceae. Entre las hierbas epífitas sobresalen las familias Bromeliaceae y Orchidaceae.

Las especies trepadoras de porte herbáceo son frecuentes. Entre las más comunes podemos mencionar a Clitoria mexicana, Dioscorea jaliscana, D. militaris, Galium mexicanum, Gaudichaudia cycloptera, Ipomoea decemcornuta, Mandevilla syrinx, Melothria pringlei, Passiflora exsudans, Phaseolus coccineus y P. micranthus. Clematis rhodocarpa, C. acapulcensis y Serjania flaviflora son las representantes leñosas más frecuentes.

Vegetación secundaria derivada del BTS (VS). Se incluye bajo este nombre a las comunidades naturales de plantas que se establecen como consecuencia de la destrucción parcial o total de la vegetación primaria o clímax, realizada directamente por el hombre o sus animales domésticos, o bien especies remanentes que se han dejado después de eliminar la mayor parte de la carpeta vegetal, como árboles de sombra o especies forrajeras. En el área de estudio, la VS ocupa $6.5 \%$ de la superficie. Se desarrolla entre 1100 y $1360 \mathrm{~m}$ de altitud y deriva del BTS. La apertura de la vegetación original se realizó con el propósito de crear mejores condiciones para el apacentamiento de ganado bovino y para mantener esta condición, con cierta regularidad, se recurre al fuego.

Aunque el número de especies arbóreas es considerable, los individuos se encuentran dispersos en el área, lo que da un aspecto de bosque muy abierto en el que predomina el estrato herbáceo con una gran densidad de gramíneas. Los árboles más comunes son Acacia farnesiana, A. macracantha, Casearia corymbosa, Cecropia obtusifolia, Cochlospermum vitifolium, Diphysa floribunda, Enterolobium cyclocarpum, Guazuma ulmifolia, Hamelia xorullensis, Indigofera thibaudiana, Leucaena macrophylla, Plumeria rubra, Pseudobombax ellipticum, Randia aculeata, Stemmadenia tomentosa y Zanthoxylum mollissimum. 
El estrato arbustivo es más denso que el arbóreo y entre los elementos más representativos podemos mencionar Acalypha cincta, Allosidastrum hilarianum, Ayenia abutilifolia, Baccharis trinervis, Calea urticifolia, Corchorus hirsutus, Eupatorium collinum, E. odoratum, Galphimia langlassei, Hyptis mutabilis, Lantana frutilla, Liabum glabrum, Lopezia semeiandra, Phyllanthus mocinianus y Senna hirsuta.

El estrato herbáceo es muy denso y las familias más diversas son Acanthaceae, Asteraceae, Leguminosae, Malvaceae y Poaceae, mientras que por densidad, la más importante es Poaceae. Las hierbas rupícolas y epífitas son muy escasas. Entre las rupícolas podemos mencionar a Achimenes longiflora y Aulosepalum nelsonii. Oncidium cebolleta es la epífita más común. Las trepadoras pueden llegar a ser frecuentes, entre las de porte leñoso destacan Amphilophium paniculatum, Clematis rhodocarpa, Mimosa diplotricha, Solanum refractum, Tetrapterys mexicana y Tournefortia hirsutissima. Mientras que de las de porte herbáceo, las más comunes son Cissampelos pareira, Ipomoea ampullacea, I. triloba, Matelea pavonii, Polyclathra cucumerina y Rytidostylis gracilis.

Bosque de pino (BP). En el área de estudio, es la comunidad vegetal con menor representación. Ocupa aproximadamente $2.5 \%$ de la superficie. Se encuentra en pequeños rodales en sitios muy pedregosos y escarpados, entre 1580 y $1900 \mathrm{~m}$ de altitud. Presenta sólo un estrato arbóreo de 15 a $25 \mathrm{~m}$ de altura dominado por Pinus douglasiana y P. oocarpa. Esporádicamente, se observan algunos individuos de Quercus scytophylla de menor tamaño. Los arbustos son escasos y los más representativos son Hyptis oblongifolia, Porophyllum lindenii y Tibouchina scabriuscula. El estrato herbáceo es poco denso y destacan por su número de especies las familias Asteraceae, Leguminosae y Poaceae. Las epífitas son escasas, al igual que las trepadoras; sin embargo, existen algunas rastreras que se comportan como trepadoras al encontrar un soporte, la más común es Clitoria mexicana.

Ecotono entre BMM y BQ (ECT). En la naturaleza es frecuente no encontrar una delimitación clara entre los diferentes tipos de vegetación. Esto se debe a que en algunas áreas son intermedias las condiciones ambientales y allí la composición de especies no permite asignarlas a una comunidad vegetal de las previamente reconocidas. Estas zonas representan sitios donde se entrelazan especies que caracterizan a más de una de ellas y se les denomina ecotonos. En algunos casos pueden llegar a cubrir cinturones importantes, tal es el nuestro. Aquí, la superficie de convergencia entre el BQ y el BMM ocupa 3.1\% del área, siendo incluso mayor que la cubierta 
por el BP. Por esta razón se decidió considerarla por separado de las comunidades vegetales que la conforman.

El ecotono se encuentra entre 1380 y $1560 \mathrm{~m}$ de altitud. Presenta una compleja estratificación vertical, dominada en la capa más alta por individuos caducifolios de Quercus excelsa, Q. iltisii y $Q$. sororia, que llegan a tener hasta $20 \mathrm{~m}$ de altura y dejan muchos espacios abiertos lo que permite el crecimiento de varios estratos inferiores. La segunda capa arbórea es apenas unos metros más baja y las especies más comunes son Inga vera, Matudaea trinervia, Oreopanax peltatus, Prunus brachybotrya y Styrax ramirezii. Un tercer estrato arbóreo, que oscila entre 3 y 10 m de altura, está dominado por Annona cherimola, Ardisia densiflora, Calliandra longipedicellata, Conostegia xalapensis, Croton draco, Cupania aff. scrobiculata, Eupatorium hebebotryum, Euphorbia cotinifolia, Gymnanthes riparia, Myrsine coriacea, Piper villiramulum, Arachnothryx leucophylla, Rogiera amoena, Senna nicaraguensis y Wimmeria lanceolata.

El estrato arbustivo es muy denso y en algunos casos es difícil de separar del arbóreo más bajo. Entre las especies más comunes podemos mencionar a Ageratum corymbosum, Ardisia compressa, Chiococca alba, Clidemia submontana, Croton ynesae, Eupatorium cylindricum, Lasianthaea macrocephala, Lycianthes surotatensis, Piper umbellatum, P. rosei, Pseudabutilon ellipticum, Tephrosia macrantha, Triumfetta galeottiana, Verbesina sphaerocephala, Vernonia cordata y V. koelzii.

La cubierta herbácea es poco frecuente, y sólo en las áreas abiertas se concentra una cantidad considerable de hierbas, entre las que destacan plantas de la familia Asteraceae. Las epífitas y rupícolas son escasas. Las especies de trepadoras también son poco frecuentes, aunque pueden llegar a tener densidades considerables en los claros. Entre las de porte herbáceo destaca la familia Convolvulaceae, mientras que en las leñosas podemos encontrar especies de Paullinia (Sapindaceae).

\section{DISCUSIÓN}

El número de especies de plantas vasculares encontradas en la parte superior del arroyo Agua Fría es menor que el de algunos sectores cercanos. En la Estación Biológica de Chamela, Lott (1985) registró la presencia de 749. Cuevas et al. (2004) dieron cuenta de la presencia de 848 en la Estación Científica Las Joyas y Sanders (1992) encontró 885 especies en la Reserva El Jabalí. Sin embargo, a estas porciones estudiadas les corresponden superficies cinco, cuatro y 15 veces mayores que el área del arroyo de Agua Fría. La gran diversidad de esta última se atribuye a su amplio 
gradiente altitudinal, lo que aunado a la compleja topografía, determina una gran heterogeneidad ambiental.

Las 115 familias, 394 géneros y 667 especies de Magnoliophyta, registradas en esta contribución, representan $79.3 \%, 52.1 \%$ y $36.9 \%$ de los respectivos taxones según lo estimado por Villaseñor (2003) para el estado de Colima, y 46.3\%, 14.7\% y $3 \%$, respectivamente, de los del país, según el mismo autor.

La proporción de helechos y plantas afines existentes en el área de estudio es mayor a 5\% estimado por Riba (1998) para México, aunque de menores dimensiones que el registrado para áreas cercanas como la Estación Científica Las Joyas (Cuevas et al., 2004). El alto porcentaje de epífitas en el arroyo de Agua Fría podría deberse a las condiciones ambientales favorables, para el grupo, que se presentan en el BMM. Las familias Asteraceae, Leguminosae y Poaceae, son las más ricas en número de especies, lo que es coincidente con lo registrado para la República Mexicana (Rzedowski, 1991; Villaseñor, 2003). Al analizar la distribución de las familias por tipo de vegetación, el orden cambia, así en el BMM, Leguminosae ocupa el primer lugar, Asteraceae el segundo y Poaceae el sexto. Algo similar se observa en México, donde la importancia relativa de las familias varía dependiendo de la región. Así Asteraceae y Poaceae están mejor representadas en el norte y centro del país, mientras que la riqueza de las Leguminosae aumenta con el incremento de la temperatura (Rzedowski, 1991). Llama la atención este último punto, pues es en el BMM donde este último grupo presenta la mayor riqueza de especies, lo que podría deberse a la importancia que tienen algunos de sus géneros en las zonas frescas del país, caso que se discute más adelante.

Euphorbiaceae y Rubiaceae son también de las familias más diversificadas en México (Villaseñor, 2003). Ambas tienen preferencia por las regiones tropicales y subtropicales del mundo (Cronquist, 1981; Rzedowski y Rzedowski, 2001). Euphorbiaceae presenta un centro de diversificación en el occidente de México (McVaugh, 1961) y Rubiaceae es considerada entre las familias mejor representadas en los tipos de vegetación de las zonas tropicales (Rzedowski, 1978).

Orchidaceae ocupa el sexto lugar en el área de estudio y el quinto en el $\mathrm{BMM}$, patrón diferente al registrado para México, donde tiene el cuarto (Rzedowski, 1991; Villaseñor, 2003) y el primero en el BMM mexicano (Rzedowski, 1978 y 1996). Lo anterior podría deberse a la falta de suficiente humedad en el arroyo de Agua Fría, pues es una familia que presenta una gran diversificación en lugares con mayor incidencia de agua tanto vertical como horizontal, sobre todo en las regiones tropicales (Cronquist, 1981). En la Estación de Biología Chamela, donde la precipitación es en promedio de sólo $733 \mathrm{~mm}$ anuales, ocupa el lugar 
número 11 por su número de especies, mientras que en la Estación Científica Las Joyas, donde la cantidad de lluvia recibida al año llega a ser hasta de $1826 \mathrm{~mm}$, la familia es la segunda más diversa.

Los 14 géneros con mayor riqueza concentran 113 especies (15.8\%). De éstos, Eupatorium y Quercus son un claro ejemplo de los que han tenido una gran diversificación en las zonas de clima semihúmedo y fresco del país (Rzedowski, 1991), condiciones que se reúnen en el BQ del área de estudio y donde se registra el mayor número de representantes de los dos géneros. A este respecto cabe reconocer que el estado de Colima se ubica entre las tres regiones con mayor riqueza de especies de Quercus en México (Nixon, 1998).

Desmodium crece en las zonas tropicales y templadas del mundo (McVaugh, 1987; Rzedowski y Rzedowski, 2001) y presenta un centro de diversificación en el país (McVaugh, 1987). En nuestro caso, este género revela mayor riqueza en el BMM, lo que podría justificar la ventaja de Leguminosae ante las Asteraceae en este tipo de vegetación. Peperomia tiene el mayor número de especies en el BMM del área, lo cual coincide con lo registrado para México (Rzedowski, 1991). Euphorbia e Ipomoea son géneros que se distribuyen mayormente en las partes tropicales y subtropicales del mundo (Cronquist, 1981) y presentan una gran diversificación en las zonas calientes de la vertiente del Pacífico (Lott, 1985; Rzedowski, 1991). En el área están representados, primordialmente, en el BTS y en la VS que se deriva de éste.

A diferencia de lo registrado en la carta de uso de suelo (Anónimo, 1975, 1981), en la cual sólo se reconocen dos comunidades vegetales para el área, en el presente trabajo se distinguen cinco tipos de vegetación y un ecotono. El que tiene mayor extensión es el BMM y el más reducido es el BP.

Del total de especies encontradas para el área de estudio, 37.3\% son nuevos registros para Colima. Lo anterior es un indicador de la escasa exploración botánica en el estado. Con seguridad, muchas de éstas se encuentran también en otros sitios fuera del área. De las mencionadas novedades, 30 corresponden a árboles, lo que eleva a 580 el número de especies con tal forma biológica para la entidad federativa (Padilla et al., 2006).

Con base en los resultados se recomienda: a) una exploración más minuciosa del estado de Colima, pues es claro que aún falta mucho por hacer en materia de inventarios biológicos; b) puesto que el área representa una cabeza de subcuenca y cuenta con una gran riqueza de especies, de las que varias están dentro de alguna categoría de riesgo y una cantidad considerable es endémica al occidente de 
México, es conveniente establecer un programa de conservación, consensuado y desarrollado junto con los propietarios.

\section{AGRADECIMIENTOS}

Se agradece al Consejo Nacional de Ciencia y Tecnología, por la beca de postgrado otorgada al primer autor; a los propietarios del ejido Agua Fría, por su apoyo durante la fase de trabajo de campo; a Gerardo Salazar, Victor Steinmann, Eleazar Carranza, Francisco Santana-Michel, Luis Guzmán, Mollie Harker, Roberto González-Tamayo, Raymundo Ramírez y Jacqueline Reynoso, por su ayuda en la identificación del material botánico de diversas familias. Un reconocimiento especial merece el Dr. Jerzy Rzedowski por la revisión de la presente contribución y por sus valiosos comentarios y sugerencias. Agradecemos a Ulrike Grau por el resumen en inglés y a Oscar Balcazar por la elaboración de los mapas, así como al personal de los herbarios CHAPA, IBUG, IEB, IPN, MEXU y ZEA, quienes nos brindaron facilidades para la consulta de sus colecciones.

\section{LITERATURA CITADA}

Anónimo. 1975. Carta de uso del suelo 1:50,000. Hoja Minatitlán E13B33. Comisión de Estudios del Territorio Nacional (CETENAL). México D.F.

Anónimo. 1977. Carta de uso potencial 1:50,000. Hoja Minatitlán E13B33. Comisión de Estudios del Territorio Nacional (CETENAL). México D.F.

Anónimo. 1981. Síntesis geográfica de Colima y anexo cartográfico. Secretaría de Programación y Presupuesto. Coordinación Nacional de Estadística, Geografía e Informática. México D.F. 131 pp.

Anónimo. 2002. Norma Oficial Mexicana NOM-059-ECOL-2001. Protección ambientalespecies nativas de la flora y fauna silvestres-categorías de riesgo y especificaciones para su inclusión, exclusión o cambio-lista de especies en riesgo. Diario Oficial de la Federación. México, D.F.

Cronquist, A. 1981. An integrated system of classification of flowering plants. Columbia University Press. Nueva York. 1262 pp.

Cuevas, R., L. Guzmán, S. Moreno y F. J. Santana. 1998. Flora arbórea del estado de Colima: una aproximación. Resúmenes del VII Congreso Latinoamericano de Botánica y XIV Congreso Mexicano de Botánica. Sociedad Botánica de México. México, D.F. pp. 225. 
Cuevas, R. y J. Rzedowski. 1999. Una especie nueva de Bursera (Burseraceae) del occidente de México. Acta Bot. Mex. 46: 77-81.

Cuevas, R., S. Koch, E. García, N. Núñez y E. J. Jardel. 2004. Flora vascular de la Estación Científica Las Joyas. In: Cuevas, R. y E. J. Jardel (eds.). Flora y vegetación de La Estación Científica Las Joyas. Universidad de Guadalajara. Guadalajara, Jalisco, México. pp. 119-176.

Dávila, P. y V. Sosa. 1994. El conocimiento florístico de México. Bol. Soc. Bot. Méx. 55: 21-27.

Flores V., O. y P. Gerez. 1994. Biodiversidad y conservación en México: vertebrados, vegetación y uso del suelo. 2a ed. Comisión Nacional para el Conocimiento y Uso de la Biodiversidad y Universidad Nacional Autónoma de México. México, D.F. 439 pp.

García, E. 1973. Modificaciones al sistema de clasificación climática de Köppen. Instituto de Geografía, Universidad Nacional Autónoma de México, México, D.F. 246 pp.

Lott, E. J. 1985. Listados florísticos de México. III. La Estación Biológica Chamela, Jalisco. Instituto de Biología, Universidad Nacional Autónoma de México. México, D.F. 47 pp.

Miranda, F. y E. Hernández-X. 1963. Los tipos de vegetación de México y su clasificación. Bol. Soc. Bot. Méx. 28: 29-179.

McVaugh, R. 1961. Euphorbiaceae novae Novo-Galicianae. Brittonia 13(2): 145-205.

McVaugh, R. 1974. Fagaceae. Flora Novo-Galiciana. Contributions from the University of Michigan Herbarium 12(1, 3): 1-93.

McVaugh, R. 1983. Gramineae. In: Anderson, W. R. (ed.). Flora Novo-Galiciana. 14. University of Michigan Press. Ann Arbor, Michigan. 436 pp.

McVaugh, R. 1984. Compositae. In: Anderson, W. R. (ed.). Flora Novo-Galiciana. 12. University of Michigan Press. Ann Arbor, Michigan. 1157 pp.

McVaugh, R. 1985. Orchidaceae. In: Anderson, W. R. (ed.). Flora Novo-Galiciana. 16. University of Michigan Press. Ann Arbor, Michigan. 363 pp.

McVaugh, R. 1987. Leguminosae. In: Anderson, W. R. (ed.). Flora Novo-Galiciana. 5. University of Michigan Press. Ann Arbor, Michigan. 786 pp.

McVaugh, R. 1989. Bromeliaceae to Dioscoreaceae. In: Anderson, W. R. (ed.). Flora NovoGaliciana. 15. University of Michigan Press. Ann Arbor, Michigan. 398 pp.

McVaugh, R. 1992. Gymnosperms and Pteridophytes. In: Anderson, W. R. (ed.). Flora Novo-Galiciana. 17. University of Michigan Press. Ann Arbor, Michigan. 467 pp.

McVaugh, R. 1993. Limnocharitaceae to Typhaceae. In: Anderson, W. R. (ed.). Flora NovoGaliciana. 13. University of Michigan Press. Ann Arbor, Michigan. 480 pp.

McVaugh, R. 2001. Ochnaceae to Loasaceae. In: Anderson, W. R. (ed.). Flora NovoGaliciana. 17. University of Michigan Press. Ann Arbor, Michigan. 751 pp.

Nixon, K. C. 1998. El género Quercus en México. In: Ramamoorthy, T. P., R. Bye, A. Lot y J. Fa (comp.). Diversidad biológica de México: orígenes y distribución. Universidad Nacional Autónoma de México. México, D.F. pp. 435-447.

Padilla, E. O., R. Cuevas y A. Solís. 2005. Inga colimana (Leguminosae) una nueva especie del occidente de México. Acta Bot. Mex. 72: 33-38. 
Padilla, E. O., R. Cuevas, G. Ibarra y S. Moreno. 2006. Riqueza y biogeografía de la flora arbórea del estado de Colima, México. Rev. Mex. Biodiv. 77: 271-295.

Pennington, T. D. y J. Sarukhán. 1998. Árboles tropicales de México. Universidad Nacional Autónoma de México y Fondo de Cultura Económica. México, D.F. 521 pp.

Riba, R. 1998. Pteridofitas mexicanas: distribución y endemismo. In: Ramamoorthy, T. P., R. Bye, A. Lot y J. Fa (comp.). Diversidad biológica de México: orígenes y distribución. Universidad Nacional Autónoma de México. México D.F. pp. 369-382.

Rzedowski, J. 1978. Vegetación de México. Limusa. México, D.F. 432 pp.

Rzedowski, J. 1991. Diversidad y orígenes de la flora fanerogámica de México. Acta Bot. Mex. 14: 3-21.

Rzedowski, J. 1996. Análisis preliminar de la flora vascular de los bosques mesófilos de montaña de México. Acta Bot. Mex. 35: 25-44.

Rzedowski, J. y R. McVaugh. 1966. La vegetación de Nueva Galicia. Contr. Univ. Mich. Herb. 9: 1-123.

Rzedowski, G. C. de y J. Rzedowski (eds.). 2001. Flora fanerogámica del Valle de México. 2a. ed. Instituto de Ecología, A.C. y Comisión Nacional para el Conocimiento y Uso de la Biodiversidad. Pátzcuaro, Michoacán. 1406 pp.

Sanders, A. 1992. Annotated checklist of the vascular flora of El Jabalí, Colima, México. In: Rothschild, B. M., E. J. Lott and A. C. Sanders (eds.). A report to the "Fundacion Ecologica de Cuixmala" on the floristic surveys of 1990-91 of the Cuixmala-Cumbres and El Jabalí reserves in México. University of California, Riverside, U.S.A. y IUCN, Richmond, U.K. pp. 107-131.

Santana-Michel, F. J., S. Lemus y M. I. Vergara. 1992. Guía de excursión etnobotánica en el estado de Colima, México. Manual científico-técnico. Universidad de Colima. Colima. 20 pp.

Santana-Michel, F. J., N. Cervantes y N. Jiménez. 1998. Flora melífera del estado de Colima, México. Boletín IBUG 6(2-3): 251-277.

Sousa, M. y A. Delgado. 1998. Leguminosas mexicanas: fitogeografía, endemismo y orígenes. In: Ramamoorthy, T. P., R. Bye, A. Lot y J. Fa (comp.). Diversidad biológica de México: orígenes y distribución. Universidad Nacional Autónoma de México. México, D.F. pp. 449-500.

Styles, B. T. 1998. El género Pinus: su panorama en México. In: Ramamoorthy, T. P., R. Bye, A. Lot y J. Fa (comp.). Diversidad biológica de México: orígenes y distribución. Universidad Nacional Autónoma de México. México D.F. pp. 385-408.

Takhtajan, A. 1997. Diversity and classification of flowering plants. Columbia University Press. Nueva York. 643 pp.

Vázquez, J. A., R. Cuevas, T. S. Cochrane, H. H. Iltis, F. J. Santana y L. Guzmán. 1995. Flora de Manantlán. Sida Botanical Miscellany 13: 1-312.

Villaseñor, J. L. 2003. Diversidad y distribución de las Magnoliophyta de México. Interciencia 28(3): 160-167. 


\section{APÉNDICE}

Catálogo de plantas vasculares de la parte alta del arroyo Agua Fría, municipio de Minatitlán, Colima, México

El número de géneros y especies se menciona entre paréntesis para cada familia. La categoría de riesgo se indica con una letra superíndice después del nombre de la autoridad (A, amenazada; P, peligro de extinción; Pr, protección especial). Los registros nuevos para Colima se señalan con un asterisco en la parte superior izquierda. La forma de vida (FV) está representada por: a (arbusto), ah-p (arbusto hemiparásito), ae (arbusto epífito), A (árbol), Ah-e (árbol hemiepífito), H (hierba), He (hierba epífita), Hp (hierba parásita), Hr (hierba rupícola), Hs (hierba saprófita), Sa (subarbusto), Th (trepadora herbácea) y Tl (trepadora leñosa). El tipo de vegetación (TV) está representado por: BTS (bosque tropical subcaducifolio), BMM (bosque mesófilo de montaña), BP (bosque de pino), BQ (bosque de encino), ECT (ecotono entre bosque de encino y bosque mesófilo de montaña) y VS (vegetación secundaria). El número de colecta es el del registro del autor.

\begin{tabular}{|c|c|c|c|}
\hline TAXON & $\mathrm{FV}$ & TV & $\begin{array}{l}\text { Núm. de } \\
\text { colecta }\end{array}$ \\
\hline \multicolumn{4}{|l|}{ PSILOTOPHYTA } \\
\hline \multicolumn{4}{|l|}{ PSILOTOPSIDA } \\
\hline \multicolumn{4}{|l|}{ PSILOTACEAE (1/1) } \\
\hline${ }^{*}$ Psilotum complanatum $\mathrm{Sw} .{ }^{\mathbf{A}}$ & $\mathrm{Hr}$ & $\mathrm{BQ}$ & 1918 \\
\hline \multicolumn{4}{|l|}{ LYCOPODIOPHYTA } \\
\hline \multicolumn{4}{|l|}{ LYCOPODIOPSIDA } \\
\hline \multicolumn{4}{|l|}{ LYCOPODIACEAE (1/1) } \\
\hline${ }^{*}$ Lycopodium clavatum L. & $\mathrm{He}$ & BMM & 1357 \\
\hline \multicolumn{4}{|l|}{ SELAGINELLACEAE $(1 / 3)$} \\
\hline Selaginella pallescens (C. Presl) Spring & $\mathrm{H}$ & BTS, ECT & 1373,1838 \\
\hline Selaginella porphyrospora A. Braun & $\mathrm{H}$ & $\mathrm{BQ}$ & 2058 \\
\hline "Selaginella silvestris Aspl. & $\mathrm{H}$ & BMM & 1867 \\
\hline
\end{tabular}

\section{FILICOPHYTA}

\section{FILICOPSIDA}

ADIANTACEAE (8/12)

${ }^{*}$ Adiantum andicola Liebm.

H BMM

1322 a 
Apéndice. Continuación.

\begin{tabular}{|c|c|c|c|}
\hline TAXON & $\mathrm{FV}$ & TV & $\begin{array}{l}\text { Núm. de } \\
\text { colecta }\end{array}$ \\
\hline Adiantum braunii Mett. ex Kuhn & $\mathrm{H}$ & BMM & $1322 b$ \\
\hline Adiantum patens Willd. & $\mathrm{H}$ & BMM & 1319 \\
\hline Adiantum poiretii Wikstr. & $\mathrm{H}$ & BMM & 1358 \\
\hline Anogramma leptophylla (L.) Link & $\mathrm{H}$ & BQ & 1923 \\
\hline Bommeria pedata (Sw.) E. Fourn. & $\mathrm{H}$ & BQ & 1401 \\
\hline $\begin{array}{l}\text { Cheilanthes chaerophylla (M. Martens \& Galeotti) } \\
\text { Kunze }\end{array}$ & $\mathrm{H}$ & BQ & 2056 \\
\hline Cheilanthes kaulfussii Kunze & $\mathrm{H}$ & BQ & 1403 \\
\hline $\begin{array}{l}\text { Hemionitis subcordata (D.C. Eaton ex Davenp.) } \\
\text { Mickel }\end{array}$ & $\mathrm{H}$ & BTS & 1377 \\
\hline "Mildella intramarginalis (Kaulf. ex Link) Trevis. & $\mathrm{H}$ & VS & 1363 \\
\hline${ }^{*}$ Pellaea ternifolia (Cav.) Link & $\mathrm{Hr}$ & BQ & 1411 \\
\hline "Pteris erosa Mickel \& Beitel & $\mathrm{H}$ & BTS & 1646 \\
\hline \multicolumn{4}{|l|}{ ASPLENIACEAE (7/15) } \\
\hline $\begin{array}{l}\text { Asplenium achilleifolium (M. Martens \& Galeotti) } \\
\text { Liebm. }\end{array}$ & $\mathrm{H}$ & BTS & 1910 \\
\hline "Asplenium auriculatum $\mathrm{Sw}$. & $\mathrm{H}$ & BMM & 1359 \\
\hline *Asplenium cuspidatum Lam. & $\mathrm{He}$ & BMM & 1317 \\
\hline Asplenium formosum Willd. & $\mathrm{H}$ & BMM & 1318 \\
\hline Asplenium praemorsum $\mathrm{Sw}$. & $\mathrm{He}$ & BMM & 2044 \\
\hline Asplenium pumilum $\mathrm{Sw}$. & $\mathrm{H}$ & ECT & 1598 \\
\hline${ }^{*}$ Cystopteris fragilis (L.) Bernh. & $\mathrm{H}$ & BMM & 1360 \\
\hline Dryopteris cinnamomea (Cav.) C. Chr. & $\mathrm{He}$ & BMM & 1326 \\
\hline Dryopteris maxonii Underw. \& C. Chr. & $\mathrm{H}$ & BTS & 1656 \\
\hline Dryopteris rossii C. Chr. & $\mathrm{H}$ & BMM & 1611 \\
\hline "Elaphoglossum piloselloides (C. Presl) T. Moore & $\mathrm{H}$ & BQ & 1415 \\
\hline *Elaphoglossum sartorii (Liebm.) Mickel & $\mathrm{H}, \mathrm{Hr}$ & BMM & 1452,1615 \\
\hline *Phanerophlebia macrosora (Baker) Underw. & $\mathrm{H}$ & BTS & 1649 \\
\hline "Tectaria mexicana (Fée) C.V. Morton & $\mathrm{H}$ & BTS & 1911 \\
\hline Woodsia mollis (Kaulf.) J. Sm. & $\mathrm{H}$ & BMM & 1572 \\
\hline \multicolumn{4}{|l|}{ BLECHNACEAE (2/2) } \\
\hline Blechnum appendiculatum Willd. & $\mathrm{H}, \mathrm{Hr}$ & BMM, ECT & 1361,1718 \\
\hline "Woodwardia spinulosa M. Martens \& Galeotti & $\mathrm{H}$ & BMM & 1515 \\
\hline
\end{tabular}


Apéndice. Continuación.

\begin{tabular}{|c|c|c|c|}
\hline TAXON & $\mathrm{FV}$ & TV & $\begin{array}{l}\text { Núm. de } \\
\text { colecta }\end{array}$ \\
\hline \multicolumn{4}{|l|}{ DAVALLIACEAE $(1 / 1)$} \\
\hline $\begin{array}{l}\text { Nephrolepis undulata (Afzel. ex Sw.) J. Sm. } \\
\text { DENNSTAEDTIACEAE (1/1) }\end{array}$ & $\mathrm{Hr}$ & BMM & 1321 \\
\hline "Pteridium caudatum (L.) Maxon & $\mathrm{H}$ & $\mathrm{ECT}$ & 2098 \\
\hline \multicolumn{4}{|l|}{ OPHIOGLOSSACEAE $(1 / 1)$} \\
\hline $\begin{array}{l}\text { Ophioglossum reticulatum L. } \\
\text { POLYPODIACEAE (4/9) }\end{array}$ & $\mathrm{H}$ & BQ & 1451 \\
\hline Campyloneurum angustifolium (Sw.) Fée & $\mathrm{He}$ & BMM & 1325 \\
\hline${ }^{*}$ Campyloneurum xalapense Fée & $\mathrm{H}$ & BTS & 1462,1648 \\
\hline $\begin{array}{l}\text { Pecluma ferruginea (M. Martens \& Galeotti) } \\
\text { M.G. Price }\end{array}$ & $\mathrm{H}$ & BMM & 1362 \\
\hline Pleopeltis angusta Humb. \& Bonpl. ex Willd. & $\mathrm{He}$ & BMM & 1323 \\
\hline Pleopeltis astrolepis (Liebm.) E. Fourn. & $\mathrm{He}$ & BMM & 1316 \\
\hline Polypodium colpodes Kunze & $\mathrm{He}$ & BMM & 1320 \\
\hline $\begin{array}{l}\text { Polypodium polypodioides (L.) Watt var. } \\
\text { aciculare Weath. }\end{array}$ & $\mathrm{He}$ & BMM & 1324 \\
\hline Polypodium sanctae-rosae (Maxon) C. Chr. & $\mathrm{He}$ & BMM & 1327 \\
\hline Polypodium subpetiolatum Hook. & $\mathrm{H}, \mathrm{He}$ & BMM & 1315,1710 \\
\hline \multicolumn{4}{|l|}{ SCHIZAEACEAE $(1 / 1)$} \\
\hline Anemia phyllitidis (L.) Sw. & $\mathrm{H}$ & BTS & 1374 \\
\hline
\end{tabular}

PINOPHYTA

PINOPSIDA

PINACEAE (1/2)

Pinus douglasiana Martínez

Pinus oocarpa Schiede ex Schltdl.

$\begin{array}{lll}\text { A } & \text { BQ, BP } & 2052 \\ \text { A } & \text { BP } & 1504\end{array}$

\section{MAGNOLIOPHYTA}

MAGNOLIOPSIDA

ACANTHACEAE (11/14)

Aphelandra madrensis Lindau

$\begin{array}{lll}\text { H, Sa } & \text { BMM } & 1697,1698 \\ \text { Sa } & \text { BTS } & 1894 \\ \text { H } & \text { VS } & 2004\end{array}$


Apéndice. Continuación.

\begin{tabular}{|c|c|c|c|}
\hline TAXON & $\mathrm{FV}$ & TV & $\begin{array}{l}\text { Núm. de } \\
\text { colecta }\end{array}$ \\
\hline${ }^{*}$ Chalarothyrsus amplexicaulis Lindau & $\mathrm{H}$ & VS & 1767 \\
\hline Dicliptera sp. & $\mathrm{H}$ & BQ & 1799 \\
\hline Dyschoriste angustifolia (Hemsl.) Kuntze & $\mathrm{H}$ & BQ, BTS & 1759,1796 \\
\hline Dyschoriste hirsutissima (Nees) Kuntze & $\mathrm{H}$ & VS & 1883 \\
\hline Elytraria imbricata (Vahl) Pers. & $\mathrm{H}$ & VS & 1789 \\
\hline Henrya insularis Nees ex Benth. & $\mathrm{H}$ & BQ & 1935 \\
\hline Justicia salviiflora H.B.K. & $\mathrm{H}$ & VS & 1887 \\
\hline Justicia sp. 1 & $\mathrm{Sa}$ & BTS & 1908 \\
\hline "Justicia sp. 2 & $\mathrm{Sa}$ & ECT & 1958 \\
\hline Pseuderanthemum praecox (Benth.) Leonard & $\mathrm{H}$ & VS & 1999 \\
\hline $\begin{array}{l}\text { Ruellia stemonacanthoides (Oerst.) Hemsl. } \\
\text { ACTINIDIACEAE (1/1) }\end{array}$ & $\mathrm{H}$ & BQ & 1747 \\
\hline $\begin{array}{l}\text { Saurauia serrata DC. }{ }^{\text {Pr }} \\
\text { AMARANTHACEAE (4/7) }\end{array}$ & A & $\mathrm{BMM}$ & 1342 \\
\hline Achyranthes aspera $\mathrm{L}$. & $\mathrm{H}$ & BMM, VS & 1567,1776 \\
\hline${ }^{*}$ Alternanthera lanceolata (Benth.) Schinz & $\mathrm{H}$ & $\mathrm{BMM}$ & 1288 \\
\hline Iresine diffusa Humb. \& Bonpl. ex Willd. & $\mathrm{H}$ & BMM, VS & 1667,1780 \\
\hline "Iresine interrupta Benth. & $\mathrm{Sa}$ & BMM & 1984 \\
\hline Iresine nigra Uline \& W.L. Bray & $\mathrm{H}$ & VS & 1886 \\
\hline Iresine sp. & $\mathrm{Tl}$ & BMM & 1954 \\
\hline $\begin{array}{l}\text { "Pleuropetalum sprucei (Hook. f.) Standl. } \\
\text { ANACARDIACEAE }(2 / 2)\end{array}$ & $\mathrm{Sa}$ & BTS & 1459 \\
\hline "Rhus terebinthifolia Schltdl. \& Cham. & $\mathrm{a}$ & BTS & 1897 \\
\hline $\begin{array}{l}\text { Toxicodendron radicans (L.) Kuntze } \\
\text { ANNONACEAE (1/2) }\end{array}$ & $\mathrm{Tl}$ & BMM & 1334 \\
\hline Annona cherimola Mill. & A & $\mathrm{ECT}$ & 2012 \\
\hline $\begin{array}{l}\text { Annona reticulata } \mathrm{L} \text {. } \\
\text { APIACEAE }(5 / 6)\end{array}$ & A & BTS & 1793 \\
\hline $\begin{array}{l}\text { *Donnellsmithia mexicana (B.L. Rob.) Mathias } \\
\text { \& Constance }\end{array}$ & $\mathrm{H}$ & BQ & 1393 \\
\hline Donnellsmithia sp. & $\mathrm{H}$ & BQ & 1410,2049 \\
\hline Enantiophylla heydeana J.M. Coult. \& Rose & $\mathrm{Sa}$ & BQ & 1527 \\
\hline${ }^{*}$ Eryngium mexiae Constance & $\mathrm{H}$ & BMM & 1940 \\
\hline
\end{tabular}


Apéndice. Continuación.

\begin{tabular}{|c|c|c|c|}
\hline TAXON & FV & TV & $\begin{array}{l}\text { Núm. de } \\
\text { colecta }\end{array}$ \\
\hline${ }^{*}$ Micropleura renifolia Lag. & $\mathrm{H}$ & BMM & 1301 \\
\hline Spananthe paniculata Jacq. & $\mathrm{H}$ & VS & 1546 \\
\hline \multicolumn{4}{|l|}{ APOCYNACEAE (7/7) } \\
\hline Alstonia pittieri (Donn. Sm.) A.H. Gentry & A & $\mathrm{BQ}$ & 1447,1816 \\
\hline Macroscepis sp. & $\mathrm{Tl}$ & BTS & 1902 \\
\hline Mandevilla syrinx Woodson & $\mathrm{Tl}$ & BQ & 1389 \\
\hline Plumeria rubra $\mathrm{L}$. & $\mathrm{A}$ & BTS & 2101 \\
\hline Prestonia mexicana A. DC. & $\mathrm{Tl}$ & BTS & 2010 \\
\hline Stemmadenia tomentosa Greenm. & $\mathrm{A}$ & VS & 1878 \\
\hline${ }^{*}$ Thenardia floribunda H.B.K. & $\mathrm{Tl}$ & $\mathrm{BMM}$ & 1330 \\
\hline \multicolumn{4}{|l|}{ ARALIACEAE $(2 / 3)$} \\
\hline Dendropanax arboreus (L.) Decne. \& Planch. & $\mathrm{A}$ & BMM & 130 \\
\hline $\begin{array}{l}\text { *Oreopanax echinops (Schltdl. \& Cham.) Decne. } \\
\text { \& Planch. }\end{array}$ & A & BMM, BTS & 1512,1895 \\
\hline Oreopanax peltatum Linden & A & $\mathrm{ECT}$ & 1839 \\
\hline \multicolumn{4}{|l|}{ ASCLEPIADACEAE (4/5) } \\
\hline "Asclepias auriculata H.B.K. & $\mathrm{H}$ & $\mathrm{BQ}$ & 1382 \\
\hline *Asclepias linaria Cav. & $\mathrm{H}$ & BQ & 1397 \\
\hline "Gonolobus uniflorus H.B.K. & $\mathrm{Tl}$ & $\mathrm{BQ}$ & 2063 \\
\hline Matelea pavonii (Decne.) Woodson & $\mathrm{Tl}$ & VS & 2068 \\
\hline Metastelma sp. & $\mathrm{Th}$ & $\mathrm{BMM}$ & 2047 \\
\hline \multicolumn{4}{|l|}{ ASTERACEAE (49/92) } \\
\hline Ageratum corymbosum Zuccagni & $\mathrm{Sa}$ & $\mathrm{BQ}, \mathrm{ECT}, \mathrm{BP}$ & $\begin{array}{l}1497,1681, \\
1842\end{array}$ \\
\hline${ }^{*}$ Archibaccharis asperifolia (Benth.) S.F. Blake & $\mathrm{a}$ & BMM & 1948 \\
\hline Baccharis trinervis Pers. & $\mathrm{a}$ & VS & 1980 \\
\hline $\begin{array}{l}\text { Bidens bigelovii A. Gray var. angustiloba (DC.) } \\
\text { Ballard }\end{array}$ & $\mathrm{H}$ & BMM & 1566 \\
\hline "Bidens mollifolia Sherff & $\mathrm{H}$ & BQ & 1530 \\
\hline${ }^{*}$ Bidens pringlei Greenm. & $\mathrm{H}$ & BQ & 1390 \\
\hline $\begin{array}{l}\text { Bidens reptans (L.) G. Don ex Sweet var. urbanii } \\
\text { (Greenm.) O.E. Schulz }\end{array}$ & $\mathrm{H}$ & BTS & 1912 \\
\hline $\begin{array}{l}\text { Bidens riparia H.B.K. var. refracta (Brandegee) } \\
\text { O.E. Schulz }\end{array}$ & $\mathrm{H}$ & BMM, VS & 1560,1568 \\
\hline Brickellia glandulosa (La Llave) McVaugh & $\mathrm{Sa}$ & VS & 1996 \\
\hline
\end{tabular}


Apéndice. Continuación.

\begin{tabular}{|c|c|c|c|}
\hline TAXON & FV & TV & $\begin{array}{l}\text { Núm. de } \\
\text { colecta }\end{array}$ \\
\hline "Brickellia jaliscensis McVaugh & $\mathrm{H}$ & $\mathrm{BP}$ & 1825 \\
\hline${ }^{*}$ Calea integrifolia (DC.) Hemsl. & $\mathrm{Sa}$ & BQ & 1930 \\
\hline${ }^{*}$ Calea palmeri A. Gray & $\mathrm{H}$ & BQ & 2060 \\
\hline Calea urticifolia (Mill.) DC. & $\mathrm{a}$ & VS & 1973 \\
\hline Carminatia recondita McVaugh & $\mathrm{H}$ & $\mathrm{BMM}$ & 1716 \\
\hline Dahlia coccinea Cav. & $\mathrm{H}$ & ECT & 1485 \\
\hline${ }^{*}$ Delilia biflora (L.) Kuntze & $\mathrm{H}$ & BTS & 1737 \\
\hline Desmanthodium fruticosum Greenm. & $\mathrm{a}$ & BQ & 1445 \\
\hline Dyssodia squamosa A. Gray & $\mathrm{H}$ & BTS & 1899 \\
\hline Elephantopus mollis H.B.K. & $\mathrm{H}$ & ECT & 1721 \\
\hline Erigeron polycephalus (Larsen) G.L. Nesom & $\mathrm{H}$ & ECT & 1844 \\
\hline "Eupatorium areolare DC. & $\mathrm{a}$ & BQ & 1683 \\
\hline${ }^{*}$ Eupatorium arsenei B.L. Rob. & $\mathrm{H}$ & ECT & 1957 \\
\hline${ }^{*}$ Eupatorium blepharilepis Sch. Bip. & $\mathrm{H}$ & BP & 1942 \\
\hline Eupatorium collinum DC. & $\mathrm{a}$ & VS & 1770 \\
\hline${ }^{*}$ Eupatorium cylindricum McVaugh & $\mathrm{a}, \mathrm{A}$ & ECT & 2013 \\
\hline${ }^{*}$ Eupatorium dolichobasis McVaugh & $\mathrm{H}$ & BQ & 1931 \\
\hline "Eupatorium hebebotryum (DC.) Hemsl. & $\mathrm{a}, \mathrm{A}$ & $\mathrm{BQ}, \mathrm{ECT}$ & 1723,1798 \\
\hline${ }^{*}$ Eupatorium lasioneuron Hook. \& Arn. & $\mathrm{a}$ & BQ & 1932 \\
\hline Eupatorium monanthum Sch. Bip. & $\mathrm{a}$ & BTS & 1964 \\
\hline Eupatorium odoratum $\mathrm{L}$. & $\mathrm{a}$ & VS & 1788 \\
\hline Eupatorium ovaliflorum Hook. \& Arn. & $\mathrm{a}$ & BQ & 1919,1920 \\
\hline "Eupatorium pycnocephalum Less. & $\mathrm{H}$ & BTS & 1906 \\
\hline Eupatorium quadrangulare DC. & a & BTS & 1909 \\
\hline Eupatorium scabrellum B.L. Rob. & $\mathrm{H}$ & BQ & 1684 \\
\hline${ }^{*}$ Eupatorium schaffneri Sch. Bip. ex B.L. Rob. & $\mathrm{H}$ & BMM & 1701 \\
\hline Fleischmannia arguta (H.B.K.) B.L. Rob. & $\mathrm{H}$ & VS & 1982 \\
\hline Gnaphalium attenuatum DC. var. attenuatum & $\mathrm{H}$ & BMM & 1702 \\
\hline Gnaphalium attenuatum var. sylvicola McVaugh & $\mathrm{H}$ & $\mathrm{BP}$ & 1826 \\
\hline Guardiola tulocarpus A. Gray & $\mathrm{Sa}$ & BMM & 1294 \\
\hline "Hieracium abscissum Less. & $\mathrm{H}$ & $\mathrm{BQ}$ & 1387 \\
\hline $\begin{array}{l}\text { Hofmeisteria dissecta (Hook. \& Arn.) R.M. King \& } \\
\text { H. Rob. }\end{array}$ & $\mathrm{H}$ & ECT & 1722 \\
\hline
\end{tabular}


Apéndice. Continuación.

\begin{tabular}{|c|c|c|c|}
\hline TAXON & $\mathrm{FV}$ & TV & $\begin{array}{l}\text { Núm. de } \\
\text { colecta }\end{array}$ \\
\hline $\begin{array}{l}\text { Hofmeisteria urenifolia (Hook. \& Arn.) Walp. var. } \\
\text { urenifolia }\end{array}$ & $\mathrm{H}$ & ECT & 1835 \\
\hline Jaegeria hirta (Lag.) Less. & $\mathrm{H}$ & VS & 2096 \\
\hline *Jaegeria macrocephala Less. & $\mathrm{H}$ & BMM & 1293 \\
\hline Lasianthaea fruticosa (L.) K.M. Becker & $\mathrm{a}$ & BQ & 1443 \\
\hline $\begin{array}{l}\text { Lasianthaea macrocephala (Hook. \& Arn.) K.M. } \\
\text { Becker }\end{array}$ & $\mathrm{a}$ & ECT & 1593 \\
\hline Liabum glabrum Hemsl. var. hypoleucum Greenm. & a & VS & 1787 \\
\hline Melampodium perfoliatum (Cav.) H.B.K. & $\mathrm{H}$ & BMM & 1564 \\
\hline Melampodium tepicense B.L. Rob. & $\mathrm{H}$ & $\mathrm{BMM}, \mathrm{BQ}$ & 1300,2059 \\
\hline $\begin{array}{l}\text { "Microspermum michoacanum (R.M. King) B.L. } \\
\text { Turner }\end{array}$ & $\mathrm{Hr}$ & BQ & 1414 \\
\hline Milleria quinqueflora $\mathrm{L}$. & $\mathrm{H}$ & VS & 1562 \\
\hline Montanoa bipinnatifida (Kunth) K. Koch & A & BMM & 1866 \\
\hline Montanoa karvinskii DC. & $\mathrm{a}$ & BTS & 1673 \\
\hline Oxypappus scaber Benth. & $\mathrm{H}$ & $\mathrm{BQ}, \mathrm{BP}$ & 1413,1501 \\
\hline${ }^{*}$ Pericalia michoacana (B.L. Rob.) Rydb. & $\mathrm{H}$ & $\mathrm{BQ}$ & 1818 \\
\hline $\begin{array}{l}\text { *Perymenium buphthalmoides DC. var. occidentale } \\
\text { McVaugh }\end{array}$ & $\mathrm{H}$ & BQ & 1399 \\
\hline *Perymenium uxoris McVaugh & $\mathrm{a}$ & BMM & 1714 \\
\hline *Piqueria triflora Hemsl. & $\mathrm{H}$ & BMM & 1313 \\
\hline Pluchea salicifolia (Mill.) S.F. Blake & $\mathrm{Sa}$ & VS & 1977 \\
\hline Podachaenium eminens (Lag.) Sch. Bip. & A & BTS & 1969 \\
\hline *Polymnia mcvaughii J.R. Wells & $\mathrm{H}$ & ECT & 1850 \\
\hline${ }^{*}$ Porophyllum lindenii Sch. Bip. & $\mathrm{Sa}$ & $\mathrm{BP}$ & 1827 \\
\hline *Psacalium peltigerum (B.L. Rob. \& Seaton) Rydb. & $\mathrm{H}$ & $\mathrm{BQ}$ & 1384 \\
\hline Pseudelephantopus spicatus (Juss. ex Aublet) Rohr & $\mathrm{H}$ & VS & 1792 \\
\hline *Rumfordia floribunda DC. & $\mathrm{a}$ & BMM & 1947 \\
\hline Senecio chapalensis $\mathrm{S}$. Watson & $\mathrm{a}$ & BTS & 1970 \\
\hline *Senecio galicianus McVaugh & $\mathrm{H}$ & $\mathrm{BQ}$ & 1688 \\
\hline *Senecio roldana DC. & $\mathrm{Sa}$ & BQ & 1817 \\
\hline *Senecio suffultus (Greenm.) McVaugh & $\mathrm{H}$ & BMM & 1638 \\
\hline Sigesbeckia agrestis Poepp. \& Endl. & $\mathrm{H}$ & BTS & 1891 \\
\hline Simsia annectens S.F. Blake & $\mathrm{H}$ & VS & 1884 \\
\hline
\end{tabular}


Apéndice. Continuación.

\begin{tabular}{|c|c|c|c|}
\hline TAXON & FV & TV & $\begin{array}{l}\text { Núm. de } \\
\text { colecta }\end{array}$ \\
\hline Sonchus oleraceus L. & $\mathrm{H}$ & BQ & 1539 \\
\hline Spilanthes alba L'Hér. & $\mathrm{H}$ & BTS & 1738 \\
\hline Stevia caracasana DC. & $\mathrm{H}$ & BTS & 1903 \\
\hline${ }^{*}$ Stevia micradenia B.L. Rob. & $\mathrm{H}$ & $\mathrm{BP}$ & 2097 \\
\hline Stevia origanoides H.B.K. & $\mathrm{H}$ & BQ & 1680 \\
\hline Stevia ovata Willd. & $\mathrm{H}$ & BQ & 1813 \\
\hline${ }^{*}$ Stevia subpubescens Lag. & $\mathrm{Sa}$ & BQ & 1921 \\
\hline Stevia sp. & $\mathrm{H}$ & BMM, BQ & 1632,1712 \\
\hline Tagetes filifolia Lag. & $\mathrm{H}$ & BQ & 1439 \\
\hline Tagetes remotiflora Kunze & $\mathrm{H}$ & BQ & 1431 \\
\hline $\begin{array}{l}\text { "Tithonia calva Sch. Bip. var. lancifolia (B.L. Rob. } \\
\text { \& Greenm.) McVaugh }\end{array}$ & $\mathrm{Sa}$ & BQ & 1682 \\
\hline Tithonia rotundifolia (Mill.) S.F. Blake & $\mathrm{H}$ & BTS & 1675 \\
\hline Verbesina greenmanii Urb. & $\mathrm{a}$ & BQ & 1686 \\
\hline Verbesina oligantha B.L. Rob. & A & BTS & 1913 \\
\hline $\begin{array}{l}\text { "Verbesina oncophora B.L. Rob. \& Seaton var. } \\
\text { subhamata McVaugh }\end{array}$ & $\mathrm{a}$ & BQ & 1687 \\
\hline Verbesina sphaerocephala A. Gray & $\mathrm{a}$ & ECT & 1596 \\
\hline Vernonia cordata H.B.K. var. hooveri McVaugh & $\mathrm{a}$ & ECT & 2014 \\
\hline Vernonia koelzii McVaugh & $\mathrm{a}$ & ECT & 1853 \\
\hline $\begin{array}{l}\text { Viguiera cordata (Hook. \& Arn.) D'Arcy var. } \\
\text { cordata }\end{array}$ & $\mathrm{H}$ & ECT & 1852 \\
\hline $\begin{array}{l}\text { "Viguiera cordata (Hook. \& Arn.) D'Arcy var. } \\
\text { websteri (B.L. Turner) McVaugh }\end{array}$ & $\mathrm{H}$ & BTS & 1905 \\
\hline Viguiera sp. 1 & $\mathrm{H}$ & BQ & 1945 \\
\hline Viguiera sp. 2 & $\mathrm{H}$ & VS & 1974 \\
\hline $\begin{array}{l}\text { Zinnia maritima H.B.K. } \\
\text { BEGONIACEAE (1/7) }\end{array}$ & $\mathrm{H}$ & $\mathrm{BMM}$ & 1341 \\
\hline "Begonia balmisiana Balmis & $\mathrm{H}$ & BMM & 1333,1509 \\
\hline Begonia biserrata Lindl. & $\mathrm{H}$ & VS & 1380 \\
\hline${ }^{*}$ Begonia aff. gracilior Burt-Utley \& McVaugh & $\mathrm{H}$ & BMM & 1351 \\
\hline${ }^{*}$ Begonia gracilis H.B.K. & $\mathrm{H}$ & BMM & 1331 \\
\hline${ }^{*}$ Begonia aff. lachaoensis Ziesenh. & $\mathrm{H}$ & BTS & 2066 \\
\hline${ }^{*}$ Begonia stigmosa Lindl. & $\mathrm{H}$ & BTS & 1961 \\
\hline
\end{tabular}


Apéndice. Continuación.

\begin{tabular}{|c|c|c|c|}
\hline TAXON & $\mathrm{FV}$ & TV & $\begin{array}{l}\text { Núm. de } \\
\text { colecta }\end{array}$ \\
\hline $\begin{array}{l}{ }^{*} \text { Begonia uruapensis Sessé \& Moc. } \\
\text { BERBERIDACEAE }(1 / 1)\end{array}$ & $\mathrm{H}$ & BMM, BTS & 1578,1734 \\
\hline $\begin{array}{l}{ }^{*} \text { Berberis aff. gracilis Benth. var. madrensis Marroq. } \\
\text { BETULACEAE (1/1) }\end{array}$ & A & $\mathrm{ECT}$ & 1836 \\
\hline $\begin{array}{l}\text { Carpinus tropicalis (Donn. Sm.) Lundell }{ }^{\mathbf{A}} \\
\text { BIGNONIACEAE }(1 / 1)\end{array}$ & A & BMM & 2025 \\
\hline $\begin{array}{l}\text { Amphilophium paniculatum (L.) H.B.K. var. molle } \\
\text { (Schltdl. \& Cham.) Standl. } \\
\text { BIXACEAE }(1 / 1)\end{array}$ & $\mathrm{Tl}$ & VS & 2031 \\
\hline $\begin{array}{l}\text { Cochlospermum vitifolium (Willd.) Spreng. } \\
\text { BOMBACACEAE }(2 / 2)\end{array}$ & A & VS & 1981 \\
\hline Ceiba aesculifolia (H.B.K.) Britten \& Baker f. & A & BTS & 1756 \\
\hline $\begin{array}{l}\text { Pseudobombax ellipticum (H.B.K.) Dugand } \\
\text { BORAGINACEAE }(4 / 5)\end{array}$ & A & BTS & 2103 \\
\hline Cordia diversifolia Pav. ex DC. & A & VS & 2541 \\
\hline${ }^{*}$ Cynoglossum pringlei Greenm. & $\mathrm{H}$ & $\mathrm{BMM}$ & 1290 \\
\hline *Heliotropium rufipilum (Benth.) I.M. Johnst. & $\mathrm{H}$ & BTS, VS & 1467,1774 \\
\hline Tournefortia hirsutissima $\mathrm{L}$. & $\mathrm{Tl}$ & VS & 1997 \\
\hline $\begin{array}{l}\text { "Tournefortia petiolaris DC. } \\
\text { BRASSICACEAE }(1 / 1)\end{array}$ & $\mathrm{a}, \mathrm{A}$ & BMM & 1352,1868 \\
\hline $\begin{array}{l}\text { Erysimum sp. } \\
\text { BUDDLEJACEAE }(1 / 2)\end{array}$ & $\mathrm{Sa}$ & BMM & 1346 \\
\hline Buddleja parviflora H.B.K. & $\mathrm{a}, \mathrm{A}$ & $\mathrm{BQ}, \mathrm{ECT}$ & 1533,1843 \\
\hline $\begin{array}{l}\text { Buddleja sessiliflora } \text { H.B.K. } \\
\text { BURSERACEAE }(2 / 2)\end{array}$ & $\mathrm{a}, \mathrm{A}$ & $\mathrm{BMM}$ & 1949 \\
\hline Bursera bipinnata (DC.) Engl. & A & $\mathrm{BQ}$ & 1525 \\
\hline $\begin{array}{l}\text { Terebinthus acuminata Rose } \\
\text { CACTACEAE (1/1) }\end{array}$ & $\mathrm{A}$ & BMM & 1624 \\
\hline $\begin{array}{l}\text { Epiphyllum anguliger (Lem.) G. Don } \\
\text { CAMPANULACEAE }(2 / 4)\end{array}$ & ae & BMM & 1953 \\
\hline Diastatea micrantha (H.B.K.) McVaugh & $\mathrm{H}$ & BQ & 1679 \\
\hline${ }^{*}$ Diastatea tenera (A. Gray) McVaugh & $\mathrm{H}$ & $\mathrm{BQ}$ & 1677 \\
\hline Lobelia cordifolia (Hook. \& Arn.) McVaugh & $\mathrm{H}$ & $\mathrm{ECT}$ & 1804,2002 \\
\hline
\end{tabular}


Apéndice. Continuación.

\begin{tabular}{|c|c|c|c|}
\hline TAXON & $\mathrm{FV}$ & TV & $\begin{array}{l}\text { Núm. de } \\
\text { colecta }\end{array}$ \\
\hline $\begin{array}{l}\text { Lobelia laxiflora H.B.K. } \\
\text { CAPPARACEAE }(1 / 2)\end{array}$ & $\mathrm{H}$ & $\mathrm{BQ}, \mathrm{BP}$ & 1828,1928 \\
\hline "Cleome pilosa Benth. & $\mathrm{H}$ & BMM & 1369 \\
\hline $\begin{array}{l}\text { Cleome speciosa } \text { Raf. } \\
\text { CARYOPHYLLACEAE (4/4) }\end{array}$ & $\mathrm{H}$ & BQ & 1481 \\
\hline Arenaria lanuginosa (Michx.) Rohrb. & $\mathrm{H}$ & BMM & 1295,1307 \\
\hline Drymaria cordata (L.) Willd. ex Roem. \& Schult. & $\mathrm{H}$ & BMM & 1296 \\
\hline $\begin{array}{l}\text { "Minuartia moehringioides (Moc. \& Sessé ex DC.) } \\
\text { Mattf. }\end{array}$ & $\mathrm{Hr}$ & BMM & 1365 \\
\hline $\begin{array}{l}\text { "Stellaria cuspidata Willd. ex Schltdl. } \\
\text { CECROPIACEAE }(2 / 2)\end{array}$ & $\mathrm{H}$ & $\mathrm{BP}$ & 1499 \\
\hline Cecropia obtusifolia Bertol. & A & BTS & 2102 \\
\hline $\begin{array}{l}\text { Coussapoa purpusii Standl. } \\
\text { CELASTRACEAE }(3 / 3)\end{array}$ & Ah-e & BTS & 1962 \\
\hline${ }^{*}$ Celastrus pringlei Rose & $\mathrm{Tl}$ & BMM & 1582,2018 \\
\hline Wimmeria lanceolata Rose & A & $\mathrm{ECT}$ & 1599,1727 \\
\hline $\begin{array}{l}\text { Zinowiewia concinna } \text { Lundell }^{\mathbf{P}} \\
\text { CHLORANTHACEAE }(1 / 1)\end{array}$ & A & BMM & 1508 \\
\hline $\begin{array}{l}\text { Hedyosmum mexicanum Cordem. } \\
\text { CLETHRACEAE }(1 / 2)\end{array}$ & A & BMM & 1858 \\
\hline Clethra rosei Britton & A & BTS & 1914 \\
\hline $\begin{array}{l}\text { Clethra fragrans L.M. González \& R. Ramírez } \\
\text { CLUSIACEAE (1/1) }\end{array}$ & A & $\mathrm{BMM}$ & 2024 \\
\hline $\begin{array}{l}\text { Clusia salvinii Donn. Sm. } \\
\text { CONVOLVULACEAE (2/9) }\end{array}$ & A & BTS & 1645 \\
\hline Ipomoea ampullacea Fernald & Th & VS & 1876 \\
\hline Ipomoea cholulensis H.B.K. & Th & BQ & 1529 \\
\hline "Ipomoea decemcornuta O'Donell & Th & BQ & 1444 \\
\hline Ipomoea purpurea (L.) Roth & Th & BTS & 1733 \\
\hline Ipomoea santillanii O'Donell & Th & BTS & 1761 \\
\hline Ipomoea seducta House & Th & ECT & 1841 \\
\hline "Ipomoea spectata J.A. McDonald & Th & $\mathrm{BMM}$ & 1329 \\
\hline Ipomoea triloba $\mathrm{L}$. & Th & VS & 1765 \\
\hline
\end{tabular}


Apéndice. Continuación.

\begin{tabular}{|c|c|c|c|}
\hline TAXON & $\mathrm{FV}$ & TV & $\begin{array}{l}\text { Núm. de } \\
\text { colecta }\end{array}$ \\
\hline $\begin{array}{l}\text { "Jacquemontia pentantha (Jacq.) G. Don } \\
\text { CORNACEAE }(1 / 1)\end{array}$ & Th & ECT & 1725 \\
\hline $\begin{array}{l}\text { Cornus disciflora Sessé \& Moc. ex DC. } \\
\text { CRASSULACEAE }(1 / 2)\end{array}$ & A & $\mathrm{BMM}$ & 1857 \\
\hline *Sedum jaliscanum S. Watson & $\mathrm{Hr}$ & BMM & 1337 \\
\hline $\begin{array}{l}{ }^{*} \text { Sedum tortuosum Hemsl. } \\
\text { CUCURBITACEAE (7/9) }\end{array}$ & $\mathrm{He}$ & BQ & 1821 \\
\hline "Cyclanthera jonesii McVaugh & Th & BMM & 1368 \\
\hline${ }^{*}$ Cyclanthera langaei Cogn. & Th & BMM & 1583 \\
\hline Cyclanthera tamnoides (Willd.) Cogn. & Th & BQ & 1629 \\
\hline Melothria pringlei (S. Watson) Mart. Crov. & Th & BQ, BTS & 1468,1540 \\
\hline Polyclathra cucumerina Bertol. & Th & VS & 1771 \\
\hline "Rytidostylis gracilis Hook. \& Arn. & Th & VS & 1559 \\
\hline Schizocarpum dieterleae Kearns & Th & BMM & 1510 \\
\hline "Sechium hintonii (Paul G. Wilson) C. Jeffrey & Th & BTS & 1755 \\
\hline $\begin{array}{l}\text { Sicyos barbatus (Gentry) C. Jeffrey } \\
\text { CUSCUTACEAE }(1 / 1)\end{array}$ & Th & BTS & 1476 \\
\hline $\begin{array}{l}{ }^{*} \text { Cuscuta gracillima Engelm. } \\
\text { EBENACEAE }(1 / 1)\end{array}$ & $\mathrm{Hp}$ & VS & 1772 \\
\hline $\begin{array}{l}\text { Diospyros sp. } \\
\text { ELAEOCARPACEAE }(1 / 1)\end{array}$ & A & BTS & 1763 \\
\hline $\begin{array}{l}{ }^{*} \text { Sloanea sp. } \\
\text { ERICACEAE }(1 / 1)\end{array}$ & A & BTS & 1650,1748 \\
\hline $\begin{array}{l}\text { Arbutus xalapensis H.B.K. } \\
\text { EUPHORBIACEAE }(10 / 26)\end{array}$ & A & BQ & 1925 \\
\hline Acalypha cincta Müll. Arg. & $\mathrm{a}, \mathrm{A}$ & VS & 2029 \\
\hline *Acalypha setosa A. Rich. & $\mathrm{H}$ & BMM & 1336 \\
\hline Acalypha aff. vagans Cav. & $\mathrm{Sa}$ & BMM & 1586 \\
\hline Acalypha sp. & $\mathrm{H}$ & $\mathrm{BMM}$ & 1660 \\
\hline Astrocasia tremula (Griseb.) G.L. Webster & A & BTS & 1641 \\
\hline Bernardia mexicana (Hook. \& Arn.) Müll. Arg. & A & BQ & 2034 \\
\hline Cnidoscolus autlanensis Breckon ${ }^{\operatorname{Pr}}$ & A & $\begin{array}{l}\text { BMM, BTS, } \\
\text { ECT }\end{array}$ & 1628 \\
\hline
\end{tabular}


Apéndice. Continuación.

\begin{tabular}{|c|c|c|c|}
\hline TAXON & $\mathrm{FV}$ & TV & $\begin{array}{l}\text { Núm. de } \\
\text { colecta }\end{array}$ \\
\hline Croton draco Schltdl. & A & BTS & 1466 \\
\hline${ }^{*}$ Croton ynesae Croizat & $\mathrm{a}$ & ECT & 1487 \\
\hline Euphorbia cotinifolia L. & A & BMM, ECT & 1594,1704 \\
\hline Euphorbia graminea Jacq. & $\mathrm{H}$ & BQ, ECT, VS & $\begin{array}{l}1477,1719, \\
1731,1766\end{array}$ \\
\hline Euphorbia heterophylla $\mathrm{L}$. & $\mathrm{H}$ & VS & 1547,1785 \\
\hline Euphorbia hirta L. & $\mathrm{H}$ & VS & 1975 \\
\hline "Euphorbia multiseta Benth. & $\mathrm{Sa}$ & BMM & 1573 \\
\hline Euphorbia peritropoides (Millsp.) V.W. Steinm. & $\mathrm{a}$ & BMM & 1689 \\
\hline Euphorbia pulcherrima Willd. ex Klotzsch & A & BTS & 1795 \\
\hline Euphorbia subreniformis S. Watson & $\mathrm{H}$ & $\mathrm{BQ}$ & 1936 \\
\hline Euphorbia xalapensis H.B.K. & $\mathrm{H}$ & BMM & 1311 \\
\hline "Euphorbia sp. nov. (fide V.W. Steinm.) & $\mathrm{Sa}$ & BTS & 1896 \\
\hline *Gymnanthes riparia (Schltdl.) Klotzsch & A & ECT & 1834 \\
\hline Phyllanthus mocinianus Baill. & $\mathrm{a}, \mathrm{A}$ & VS & 2077 \\
\hline Phyllanthus standleyi McVaugh & $\mathrm{H}$ & $\mathrm{BMM}$ & 1344 \\
\hline Phyllanthus sp. 1 & $\mathrm{a}, \mathrm{A}$ & BQ & 1484 \\
\hline Phyllanthus sp. 2 & $\mathrm{a}, \mathrm{A}$ & ECT & 2093 \\
\hline Sapium sp. & $\mathrm{A}$ & VS & 2071 \\
\hline Sebastiania hintonii Lundell & A & BMM & 1669 \\
\hline \multicolumn{4}{|l|}{ FAGACEAE $(1 / 8)$} \\
\hline Quercus castanea Née & A & BMM & 1692 \\
\hline Quercus elliptica Née & A & BQ & 2027 \\
\hline *Quercus excelsa Liebm. & A & $\mathrm{BMM}$ & 1865,2043 \\
\hline Quercus iltisii L.M. González & A & $\mathrm{BQ}, \mathrm{ECT}$ & $\begin{array}{l}\text { 1741,1797, } \\
1994\end{array}$ \\
\hline Quercus rugosa Née & A & BQ & 1448,1517 \\
\hline Quercus scytophylla Liebm. & A & $\mathrm{BQ}$ & 2053 \\
\hline "Quercus sororia Liebm. & A & BQ & 1605 \\
\hline Quercus uxoris McVaugh & A & BMM & 1806,1991 \\
\hline \multicolumn{4}{|l|}{ FLACOURTIACEAE (2/2) } \\
\hline Casearia corymbosa H.B.K. & $\mathrm{a}, \mathrm{A}$ & VS & 2007 \\
\hline Xylosma flexиоsum (H.B.К.) Hemsl. & $\mathrm{a}, \mathrm{A}$ & BMM & 1620,1862 \\
\hline
\end{tabular}


Apéndice. Continuación.

\begin{tabular}{|c|c|c|c|}
\hline TAXON & FV & $\mathrm{TV}$ & $\begin{array}{l}\text { Núm. de } \\
\text { colecta }\end{array}$ \\
\hline \multicolumn{4}{|l|}{ GARRYACEAE (1/1) } \\
\hline Garrya longifolia Rose & A & BMM & 1691,1703 \\
\hline \multicolumn{4}{|l|}{ GENTIANACEAE $(2 / 2)$} \\
\hline Centaurium quitense (H.B.K.) B.L. Rob. & $\mathrm{H}$ & ECT & 1720 \\
\hline${ }^{*}$ Halenia brevicornis (H.B.K.) G. Don & $\mathrm{H}$ & $\mathrm{BQ}$ & 2001 \\
\hline \multicolumn{4}{|l|}{ GERANIACEAE $(1 / 1)$} \\
\hline Geranium seemannii Peyr. & $\mathrm{H}$ & $\mathrm{BQ}$ & 1531 \\
\hline \multicolumn{4}{|l|}{ GESNERIACEAE (3/6) } \\
\hline Achimenes antirrhina (DC.) C.V. Morton & $\mathrm{H}$ & BMM & 1353 \\
\hline Achimenes flava C.V. Morton & $\mathrm{H}$ & BTS & 1379 \\
\hline "Achimenes heterophylla (Mart.) DC. & $\mathrm{Hr}$ & BMM & 1305 \\
\hline Achimenes longiflora DC. & $\mathrm{Hr}$ & VS & 2070 \\
\hline${ }^{*}$ Drymonia serrulata (Jacq.) Mart. & $\mathrm{Tl}$ & BTS & 1378 \\
\hline Moussonia elegans Decne. & $\mathrm{a}$ & $\mathrm{BQ}$ & 1391 \\
\hline \multicolumn{4}{|l|}{ HAMAMELIDACEAE $(1 / 1)$} \\
\hline Matudaea trinervia Lundell $^{\mathbf{A}}$ & A & ECT & 2015 \\
\hline \multicolumn{4}{|l|}{ HIPPOCRATEACEAE (1/1) } \\
\hline Hippocratea celastroides H.B.K. & $\mathrm{Tl}$ & BTS & 1965 \\
\hline \multicolumn{4}{|l|}{ HYDROPHYLLACEAE (1/1) } \\
\hline "Wigandia urens (Ruiz \& Pav.) H.B.K. & a & BMM & 2547 \\
\hline \multicolumn{4}{|l|}{ ICACINACEAE $(1 / 1)$} \\
\hline Calatola laevigata Standl. & A & BTS & 1967 \\
\hline \multicolumn{4}{|l|}{ LAMIACEAE (6/14) } \\
\hline Asterohyptis stellulata (Benth.) Epling & $\mathrm{a}$ & BMM & 1664 \\
\hline Hyptis mutabilis (Rich.) Briq. & $\mathrm{Sa}$ & VS & 1784 \\
\hline${ }^{*}$ Hyptis oblongifolia Benth. & a & $\mathrm{BQ}, \mathrm{BP}$ & 1695,1822 \\
\hline "Lepechinia nelsonii (Fernald) Epling & $\mathrm{H}$ & BMM & 1861 \\
\hline${ }^{*}$ Salvia gracilis Benth. & $\mathrm{H}$ & BMM, BTS & 1668,1732 \\
\hline Salvia iodantha Fernald & $\mathrm{a}$ & $\mathrm{BQ}$ & 1915 \\
\hline "Salvia lasiocephala Hook. \& Arn. & $\mathrm{H}$ & $\mathrm{BQ}$ & 1523 \\
\hline Salvia lavanduloides Benth. & $\mathrm{H}$ & $\mathrm{BP}$ & 1502 \\
\hline Salvia mexicana $\mathrm{L}$. & $\mathrm{Sa}$ & BMM & 1565 \\
\hline${ }^{*}$ Salvia thyrsiflora Benth. & $\mathrm{Sa}$ & $\mathrm{BMM}, \mathrm{BQ}$ & 1870,1927 \\
\hline
\end{tabular}


Apéndice. Continuación.

\begin{tabular}{|c|c|c|c|}
\hline TAXON & FV & TV & $\begin{array}{l}\text { Núm. de } \\
\text { colecta }\end{array}$ \\
\hline Salvia sp. & $\mathrm{H}$ & BTS & 1736 \\
\hline "Scutellaria purpurascens Sw. & $\mathrm{H}$ & $\mathrm{BMM}$ & 1297 \\
\hline "Stachys agraria Schltdl. \& Cham. & $\mathrm{H}$ & BQ & 1416 \\
\hline $\begin{array}{l}{ }^{*} \text { Stachys manantlanensis B.L. Turner } \\
\text { LAURACEAE }(5 / 6)\end{array}$ & $\mathrm{H}$ & $\mathrm{BMM}$ & 1298 \\
\hline Beilschmiedia manantlanensis Cuevas \& Cochrane & A & BTS & 1966 \\
\hline $\begin{array}{l}\text { Cinnamomum aff. hartmannii (I.M. Johnst.) } \\
\text { Kosterm. }\end{array}$ & A & BTS & 1978 \\
\hline Litsea glaucescens H.B.K. ${ }^{\mathbf{P}}$ & $\mathrm{a}, \mathrm{A}$ & BQ & 1746 \\
\hline Nectandra sp. 1 & $\mathrm{~A}$ & ECT & $1589 \mathrm{a}$ \\
\hline Nectandra sp. 2 & $\mathrm{~A}$ & BTS, ECT & $\begin{array}{l}1589 b \\
1893\end{array}$ \\
\hline Persea hintonii C.K. Allen & A & BMM & 1739 \\
\hline \multicolumn{4}{|l|}{ LEGUMINOSAE (35/74) } \\
\hline Acacia farnesiana (L.) Willd. & $\mathrm{a}, \mathrm{A}$ & VS & 2032 \\
\hline Acacia macracantha Humb. \& Bonpl. ex Willd. & A & VS & 2073 \\
\hline $\begin{array}{l}\text { Acaciella angustissima (Mill.) Britton \& Rose var. } \\
\text { angustissima }\end{array}$ & A & BQ & 1528,1916 \\
\hline Aeschynomene americana L. var. flabellata Rudd & $\mathrm{H}$ & VS & 1764 \\
\hline $\begin{array}{l}\text { Aeschynomene villosa Poir. var. mexicana } \\
\text { (Rose) Rudd }\end{array}$ & $\mathrm{H}$ & BTS & 1971 \\
\hline Calliandra houstoniana (Mill.) Standl. & $\mathrm{a}, \mathrm{A}$ & BQ & 1779 \\
\hline Calliandra laevis Rose & $\mathrm{A}$ & BMM & 1871 \\
\hline $\begin{array}{l}\text { Calliandra longipedicellata (McVaugh) Macqueen } \\
\text { \& H.M. Hern. }\end{array}$ & $\mathrm{a}, \mathrm{A}$ & $\mathrm{BQ}, \mathrm{ECT}$ & $\begin{array}{l}1543,1801, \\
1805\end{array}$ \\
\hline${ }^{*}$ Canavalia hirsutissima J.D. Sauer & $\mathrm{Tl}$ & $\mathrm{BMM}$ & 1570 \\
\hline${ }^{*}$ Canavalia aff. septentrionalis J.D. Sauer & $\mathrm{Tl}$ & BMM, BTS & 1609,1758 \\
\hline Centrosema plumieri (Pers.) Benth. & Th & BTS & 1602 \\
\hline $\begin{array}{l}\text { "Chamaecrista punctulata (Hook. \& Arn.) H.S. } \\
\text { Irwin \& Barneby }\end{array}$ & $\mathrm{H}$ & BQ & 1744 \\
\hline${ }^{*}$ Clitoria mexicana Link & Th & $\mathrm{BQ}, \mathrm{BP}$ & 1505,1814 \\
\hline Cologania broussonetii (Balb.) DC. & Th & $\mathrm{BMM}$ & 1339 \\
\hline${ }^{*}$ Cologania cordata Fearing ex McVaugh & Th & $\mathrm{BP}$ & 1823 \\
\hline "Crotalaria bupleurifolia Schltdl. \& Cham. & $\mathrm{H}$ & BMM & 1514 \\
\hline
\end{tabular}


Apéndice. Continuación.

\begin{tabular}{|c|c|c|c|}
\hline TAXON & $\mathrm{FV}$ & TV & $\begin{array}{l}\text { Núm. de } \\
\text { colecta }\end{array}$ \\
\hline${ }^{*}$ Crotalaria filifolia Rose & $\mathrm{H}$ & BQ & 1388 \\
\hline Crotalaria longirostrata Hook. \& Arn. & $\mathrm{Sa}$ & $\mathrm{BQ}$ & 1430 \\
\hline Crotalaria micans Link & $\mathrm{a}$ & $\mathrm{BMM}$ & 1335 \\
\hline Crotalaria mollicula H.B.K. & $\mathrm{H}$ & $\mathrm{BMM}$ & 1370 \\
\hline${ }^{*}$ Crotalaria quercetorum Brandegee & $\mathrm{H}$ & $\mathrm{BQ}$ & 1449 \\
\hline Dalea cliffortiana Willd. & $\mathrm{H}$ & ECT & 1726 \\
\hline Desmodium angustifolium (H.B.K.) DC. & $\mathrm{H}$ & BQ & 1542 \\
\hline "Desmodium aparines (Link) DC. & $\mathrm{H}$ & $\mathrm{ECT}$ & 1849 \\
\hline "Desmodium cordistipulum Hemsl. & $\mathrm{H}$ & $\mathrm{BQ}$ & 1396 \\
\hline Desmodium intortum (Mill.) Urb. & $\mathrm{H}$ & $\mathrm{BP}$ & 1496 \\
\hline${ }^{*}$ Desmodium jaliscanum S. Watson & $\mathrm{a}$ & BMM & 1536 \\
\hline "Desmodium madrense Hemsl. & $\mathrm{a}$ & BMM & 1428 \\
\hline $\begin{array}{l}\text { "Desmodium michoacanum B.G. Schub. \& } \\
\text { McVaugh }\end{array}$ & $\mathrm{H}$ & BQ & 1934 \\
\hline "Desmodium occidentale (C.V. Morton) Standl. & $\mathrm{Sa}$ & BMM & 1855 \\
\hline "Desmodium prehensile Schltdl. & $\mathrm{H}$ & BMM & 1663 \\
\hline $\begin{array}{l}\text { "Desmodium skinneri Benth. ex Hemsl. var. } \\
\text { flavovirens B.G. Schub. \& McVaugh }\end{array}$ & $\mathrm{a}, \mathrm{Sa}$ & BMM, BTS & 1900,1993 \\
\hline Desmodium tortuosum (Sw.) DC. & $\mathrm{H}$ & VS & 1549 \\
\hline Desmodium sp. & $\mathrm{Th}$ & BMM & 1938 \\
\hline Diphysa floribunda Peyr. & A & VS & 1976 \\
\hline Enterolobium cyclocarpum (Jacq.) Griseb. & A & VS & 1972 \\
\hline${ }^{*}$ Eriosema diffusum (H.B.K.) G. Don & $\mathrm{H}$ & $\mathrm{BP}$ & 1500 \\
\hline Erythrina breviflora Sessé \& Moc. ex DC. & $\mathrm{a}, \mathrm{A}$ & $\mathrm{BQ}$ & 1442 \\
\hline $\begin{array}{l}\text { Erythrina lanata Rose subsp. occidentalis (Standl.) } \\
\text { Krukoff \& Barneby }\end{array}$ & A & BTS & 1735 \\
\hline Eysenhardtia platycarpa Pennell \& Saff. ex Pennell & $\mathrm{a}, \mathrm{A}$ & BQ & 1526 \\
\hline${ }^{*}$ Galactia aff. wrightii A. Gray & Th & BMM & 1607 \\
\hline Indigofera thibaudiana $\mathrm{DC}$. & A & BMM, VS & 1613,1875 \\
\hline Inga colimana Padilla-V., Cuevas \& Solis-M. & A & BTS & 1995 \\
\hline Inga micheliana Harms & A & BMM & 2026 \\
\hline $\begin{array}{l}\text { Inga vera Willd. subsp. eriocarpa (Benth.) } \\
\text { Jorge León }\end{array}$ & A & $\mathrm{ECT}$ & 1959 \\
\hline
\end{tabular}


Apéndice. Continuación.

\begin{tabular}{|c|c|c|c|}
\hline TAXON & $\mathrm{FV}$ & TV & $\begin{array}{l}\text { Núm. de } \\
\text { colecta }\end{array}$ \\
\hline Leucaena macrophylla Benth. & A & VS & 1890 \\
\hline Lonchocarpus guatemalensis Benth. & A & BTS & 122 \\
\hline${ }^{*}$ Lotus repens (G. Don) Standl. \& Steyerm. & $\mathrm{H}$ & BQ & 1419 \\
\hline Lupinus exaltatus Zucc. & $\mathrm{H}$ & BQ & 1694 \\
\hline Lysiloma acapulcense (Kunth) Benth. & A & BQ & 2054 \\
\hline${ }^{*}$ Machaerium salvadorense (Donn. Sm.) Rudd & $\mathrm{Tl}$ & BTS & 1376 \\
\hline${ }^{*}$ Marina grammadenia Barneby & a & BMM & 1808,1874 \\
\hline Mimosa affinis B.L. Rob. & $\mathrm{H}$ & VS & 1381 \\
\hline Mimosa albida Humb. \& Bonpl. & $\mathrm{Tl}$ & BTS & 1458 \\
\hline "Mimosa diplotricha $\mathrm{C}$. Wright ex Sauvalle & $\mathrm{Tl}$ & VS & 1769 \\
\hline Phaseolus coccineus $\mathrm{L}$. & Th & BQ & 1433 \\
\hline $\begin{array}{l}\text { Phaseolus micranthus Hook. \& Arn. var. } \\
\text { micranthus }\end{array}$ & Th & $\begin{array}{l}\text { BMM, BQ, } \\
\text { BTS }\end{array}$ & $\begin{array}{l}1394,1541, \\
1757,1941\end{array}$ \\
\hline Phaseolus vulgaris $\mathrm{L}$. & Th & $\mathrm{BMM}$ & 1626 \\
\hline $\begin{array}{l}\text { "Ramirezella micrantha A. Delgado \& } \\
\text { Ochoterena-Booth }\end{array}$ & Th & BMM & 1639 \\
\hline Rhynchosia aff. discolor M. Martens \& Galeotti & $\mathrm{Th}$ & $\mathrm{BMM}$ & 1986 \\
\hline "Rhynchosia elisae O. Téllez & Th & BMM, ECT & 1845,1950 \\
\hline $\begin{array}{l}\text { Senna foetidissima (G. Don) H.S. Irwin \& Barneby } \\
\text { var. grandiflora (Benth.) H.S. Irwin \& Barneby }\end{array}$ & $\mathrm{a}$ & BQ & 1685,1812 \\
\hline $\begin{array}{l}\text { Senna hirsuta (L.) H.S. Irwin \& Barneby var. hirta } \\
\text { H.S. Irwin \& Barneby }\end{array}$ & $\mathrm{a}$ & VS & 1783 \\
\hline $\begin{array}{l}\text { Senna nicaraguensis (Benth.) H.S. Irwin \& } \\
\text { Barneby }\end{array}$ & A & ECT & 1592 \\
\hline Senna obtusifolia (L.) H.S. Irwin \& Barneby & $\mathrm{Sa}$ & VS & 1548 \\
\hline $\begin{array}{l}\text { "Senna pilifera }(\text { Vogel) H.S. Irwin \& Barneby var. } \\
\text { subglabra }(\text { S. Moore) H.S. Irwin \& Barneby }\end{array}$ & $\mathrm{H}$ & VS & 1553 \\
\hline $\begin{array}{l}\text { Senna quinquangulata (Rich.) H.S. Irwin \& } \\
\text { Barneby var. quinquangulata }\end{array}$ & $\mathrm{Tl}$ & VS & 1775 \\
\hline${ }^{*}$ Tephrosia langlassei Micheli & $\mathrm{a}$ & $\mathrm{BMM}$ & 1711 \\
\hline $\begin{array}{l}\text { Tephrosia macrantha B.L. Rob. \& Greenm. } \\
\text { ex Pringle }\end{array}$ & $\mathrm{a}$ & ECT & 1724 \\
\hline $\begin{array}{l}\text { Vigna adenantha (G.F. Mey.) Maréchal, Mascherpa } \\
\text { \& Stainier }\end{array}$ & Th & BTS & 1672 \\
\hline
\end{tabular}


Apéndice. Continuación.

\begin{tabular}{|c|c|c|c|}
\hline TAXON & FV & TV & $\begin{array}{l}\text { Núm. de } \\
\text { colecta }\end{array}$ \\
\hline Vigna lozanii (Rose) Lackey ex McVaugh & $\mathrm{Th}$ & ECT & 1956 \\
\hline $\begin{array}{l}\text { Zapoteca formosa (Kunth) H.M. Hern. subsp. } \\
\text { formosa }\end{array}$ & $\mathrm{a}, \mathrm{A}$ & BTS & 2065 \\
\hline $\begin{array}{l}{ }^{*} \text { Zapoteca portoricensis (Jacq.) H.M. Hern. subsp. } \\
\text { portoricensis }\end{array}$ & $\mathrm{a}, \mathrm{A}$ & BMM & 2055 \\
\hline $\begin{array}{l}\text { Zapoteca tetragona (Willd.) H.M. Hern. } \\
\text { LOASACEAE }(1 / 1)\end{array}$ & $\mathrm{a}$ & BQ & 1778 \\
\hline $\begin{array}{l}\text { Klaprothia fasciculata (C. Presl) Poston } \\
\text { LORANTHACEAE }(3 / 3)\end{array}$ & $\mathrm{H}$ & BTS & 1473 \\
\hline Cladocolea grahamii (Benth.) Tiegh. & ah-p & $\mathrm{BQ}$ & 1924 \\
\hline $\begin{array}{l}\text { *Psittacanthus ramiflorus (Moc. \& Sessé ex DC.) } \\
\text { G. Don }\end{array}$ & ah-p & BQ & 1544 \\
\hline $\begin{array}{l}\text { *Struthanthus interruptus (H.B.K.) Blume } \\
\text { LYTHRACEAE }(1 / 7)\end{array}$ & ah-p & BMM & 2045 \\
\hline${ }^{*}$ Cuphea appendiculata Benth. & $\mathrm{H}$ & $\mathrm{BMM}$ & 1289 \\
\hline${ }^{*}$ Cuphea avigera B.L. Rob. \& Seaton var. avigera & $\mathrm{H}$ & $\mathrm{BMM}$ & 1367 \\
\hline Cuphea hookeriana Walp. & $\mathrm{H}$ & BQ & $\begin{array}{l}1437,1518 \\
1604\end{array}$ \\
\hline Cuphea leptopoda Hemsl. & $\mathrm{H}$ & VS & 2076 \\
\hline Cuphea llavea Lex. & $\mathrm{H}$ & BQ & 1482 \\
\hline Cuphea tolucana Peyr. & $\mathrm{H}$ & BQ & 1402 \\
\hline $\begin{array}{l}{ }^{*} \text { Cuphea vesiculigera } \text { R.C. Foster } \\
\text { MAGNOLIACEAE }(1 / 1)\end{array}$ & $\mathrm{H}$ & VS & 2072 \\
\hline $\begin{array}{l}\text { Magnolia iltisiana A. Vázquez } \\
\text { MALPIGHIACEAE }(5 / 7)\end{array}$ & A & BMM & 1665 \\
\hline Bunchosia lanceolata Turcz. & A & BTS & 708 \\
\hline${ }^{*}$ Bunchosia mcvaughii W.R. Anderson & A & ECT & 1833 \\
\hline Bunchosia sp. & $\mathrm{a}$ & BMM & 1511 \\
\hline *Callaeum malpighioides (Turcz.) D.M. Johnson & $\mathrm{Tl}$ & BTS & 1751 \\
\hline${ }^{*}$ Galphimia langlassei (S.F. Blake) C.E. Anderson & $\mathrm{a}, \mathrm{A}$ & $\mathrm{BQ}, \mathrm{VS}$ & 1979 \\
\hline Gaudichaudia cycloptera (DC.) W.R. Anderson & $\mathrm{Tl}$ & BQ & 1446 \\
\hline $\begin{array}{l}\text { Tetrapterys mexicana Hook. \& Arn. } \\
\text { MALVACEAE }(8 / 12)\end{array}$ & $\mathrm{Tl}$ & VS & 2006 \\
\hline $\begin{array}{l}\text { Allosidastrum hilarianum (C. Presl) Krapov., } \\
\text { Fryxell \& D.M. Bates }\end{array}$ & $\mathrm{Sa}$ & VS & 1885 \\
\hline
\end{tabular}


Apéndice. Continuación.

\begin{tabular}{|c|c|c|c|}
\hline TAXON & $\mathrm{FV}$ & TV & $\begin{array}{l}\text { Núm. de } \\
\text { colecta }\end{array}$ \\
\hline Anoda cristata (L.) Schltdl. & $\mathrm{H}$ & VS & 1492 \\
\hline Hochreutinera amplexifolia (DC.) Fryxell & $\mathrm{H}$ & VS & 1554 \\
\hline Malvaviscus arboreus Cav. & $\mathrm{a}$ & BTS & 1463 \\
\hline Pavonia pleuranthera (DC.) Fryxell & $\mathrm{a}, \mathrm{A}$ & BTS & 1904 \\
\hline Periptera ctenotricha Fryxell $\mathbf{P r}$ & $\mathrm{a}$ & BTS & 1968 \\
\hline${ }^{*}$ Periptera macrostelis Rose ${ }^{\mathrm{Pr}}$ & $\mathrm{a}$ & $\mathrm{BQ}$ & 1929 \\
\hline "Pseudabutilon ellipticum (Schltdl.) Fryxell & $\mathrm{a}$ & BMM, ECT & 1840,2020 \\
\hline Sida acuta Burm. f. & $\mathrm{H}$ & VS & 1768 \\
\hline Sida glabra Mill. & $\mathrm{H}$ & VS & 1790 \\
\hline Sida haenkeana C. Presl & $\mathrm{H}$ & BQ & 1424 \\
\hline $\begin{array}{l}\text { Sida rhombifolia } \mathrm{L} \text {. } \\
\text { MELASTOMATACEAE (7/7) }\end{array}$ & $\mathrm{H}$ & BQ & 2092 \\
\hline "Arthrostemma alatum Triana & $\mathrm{H}$ & VS & 1777 \\
\hline "Clidemia submontana Rose ex Gleason & $\mathrm{a}$ & BMM, ECT & 1345,2085 \\
\hline Conostegia xalapensis (Humb. \& Bonpl.) D. Don & $\mathrm{a}, \mathrm{A}$ & ECT & 1595 \\
\hline Heterocentron sp. & $\mathrm{Sa}$ & BQ & 1815 \\
\hline "Leandra cornoides (Schltdl. \& Cham.) Cogn. & $\mathrm{a}$ & BMM & 1569 \\
\hline Miconia sp. & $\mathrm{a}$ & BQ & 1633 \\
\hline $\begin{array}{l}{ }^{*} \text { Tibouchina scabriuscula (Schltdl.) Cogn. } \\
\text { MELIACEAE (3/3) }\end{array}$ & $\mathrm{Sa}$ & $\mathrm{BP}$ & 1495 \\
\hline Cedrela odorata $\mathrm{L}$. & A & BMM, BTS & 1983,2019 \\
\hline Guarea glabra Vahl & A & BMM & 1709,1955 \\
\hline $\begin{array}{l}\text { Trichilia americana (Sessé \& Moc.) T.D. Penn. } \\
\text { MENISPERMACEAE }(1 / 1)\end{array}$ & A & BTS & 1762 \\
\hline $\begin{array}{l}\text { Cissampelos pareira } \mathrm{L} \text {. } \\
\text { MONIMIACEAE }(1 / 1)\end{array}$ & Th & BMM, VS & 1992,1998 \\
\hline $\begin{array}{l}\text { Siparuna andina (Tul.) A. DC. } \\
\text { MONOTROPACEAE (1/1) }\end{array}$ & A & BTS & 1600 \\
\hline $\begin{array}{l}\text { "Monotropa hypopitys L. } \\
\text { MORACEAE }(3 / 8)\end{array}$ & Hs & BQ & 1606 \\
\hline Dorstenia drakena $\mathrm{L}$. & $\mathrm{H}$ & BMM & 1580 \\
\hline Ficus glycicarpa (Miq.) Miq. & A & BTS & 2091 \\
\hline
\end{tabular}


Apéndice. Continuación.

\begin{tabular}{|c|c|c|c|}
\hline TAXON & $\mathrm{FV}$ & TV & $\begin{array}{l}\text { Núm. de } \\
\text { colecta }\end{array}$ \\
\hline Ficus maxima Mill. & A & BTS & 1760 \\
\hline Ficus pertusa L. f. & $\mathrm{A}$ & VS & 2542 \\
\hline Ficus velutina Humb. \& Bonpl. ex Willd. & A & BMM & 1581 \\
\hline Ficus sp. & $\mathrm{A}$ & BMM & 1623 \\
\hline${ }^{*}$ Trophis mexicana (Liebm.) Bureau & $\mathrm{A}$ & BTS & 1963 \\
\hline $\begin{array}{l}\text { *Trophis noraminervae Cuevas \& Carvajal } \\
\text { MYRSINACEAE }(3 / 4)\end{array}$ & A & $\mathrm{BMM}$ & 1577 \\
\hline Ardisia compressa H.B.K. & $\mathrm{a}, \mathrm{A}$ & ECT & 1590 \\
\hline${ }^{*}$ Ardisia densiflora Krug \& Urb. & $\mathrm{A}$ & $\mathrm{ECT}$ & 1653 \\
\hline${ }^{*}$ Myrsine coriacea (Sw.) R. Br. ex Roem. \& Schult. & A & $\mathrm{BQ}, \mathrm{ECT}$ & $\begin{array}{l}1743,1800, \\
2028\end{array}$ \\
\hline $\begin{array}{l}\text { Parathesis villosa Lundell } \\
\text { MYRTACEAE (3/5) }\end{array}$ & A & BMM & 1588,1864 \\
\hline Eugenia capuli (Schltdl. \& Cham.) Hook. \& Arn. & A & $\mathrm{BQ}$ & 1478 \\
\hline Eugenia aff. rekoi Standl. & $\mathrm{A}$ & BMM & 1576 \\
\hline Eugenia sp. & A & BTS & 1749 \\
\hline Myrcianthes fragrans (Sw.) McVaugh & A & BMM, BTS & 1657,1872 \\
\hline $\begin{array}{l}\text { Psidium sartorianum (O. Berg) Nied. } \\
\text { NYCTAGINACEAE }(1 / 1)\end{array}$ & A & BTS & 1671 \\
\hline $\begin{array}{l}{ }^{*} \text { Mirabilis polonii Le Duc } \\
\text { OLACACEAE }(1 / 1)\end{array}$ & $\mathrm{Sa}$ & VS & 2075 \\
\hline $\begin{array}{l}{ }^{*} \text { Schoepfia vacciniflora Triana \& Planch. } \\
\text { OLEACEAE }(1 / 1)\end{array}$ & A & BTS & 1670 \\
\hline $\begin{array}{l}\text { Fraxinus uhdei (Wenz.) Lingelsh. } \\
\text { ONAGRACEAE (4/7) }\end{array}$ & A & BMM & 1951 \\
\hline${ }^{*}$ Fuchsia encliandra Steud. subsp. encliandra & $\mathrm{a}$ & BMM & 1306 \\
\hline${ }^{*}$ Fuchsia fulgens DC. & ae & BMM & 2100 \\
\hline "Fuchsia microphylla H.B.K. & $\mathrm{a}$ & BMM & 2048 \\
\hline "Gongylocarpus rubricaulis Schltdl. \& Cham. & $\mathrm{H}$ & BQ & 1425 \\
\hline Lopezia miniata DC. & $\mathrm{H}$ & $\mathrm{BQ}$ & 1522 \\
\hline $\begin{array}{l}\text { Lopezia semeiandra Plitmann, P.H. Raven \& } \\
\text { Breedlove }\end{array}$ & a & VS & 1881 \\
\hline Ludwigia octovalvis (Jacq.) P.H. Raven & $\mathrm{H}$ & VS & 1551 \\
\hline
\end{tabular}


Apéndice. Continuación.

\begin{tabular}{|c|c|c|c|}
\hline TAXON & $\mathrm{FV}$ & TV & $\begin{array}{l}\text { Núm. de } \\
\text { colecta }\end{array}$ \\
\hline \multicolumn{4}{|l|}{ OPILIACEAE (1/1) } \\
\hline $\begin{array}{l}\text { Agonandra racemosa }(\text { DC.) Standl. } \\
\text { OXALIDACEAE }(1 / 2)\end{array}$ & A & BMM & 2017 \\
\hline *Oxalis alpina (Rose) R. Knuth & $\mathrm{Hr}$ & BMM & 1338 \\
\hline $\begin{array}{l}{ }^{*} \text { Oxalis hernandezii DC. } \\
\text { PAPAVERACEAE }(1 / 1)\end{array}$ & $\mathrm{H}$ & BQ & 1423 \\
\hline $\begin{array}{l}\text { Bocconia arborea } \mathrm{S} \text {. Watson } \\
\text { PASSIFLORACEAE }(1 / 4)\end{array}$ & $\mathrm{A}$ & BTS & 1465 \\
\hline *Passiflora biflora Lam. & Th & BTS & 1655 \\
\hline *Passiflora exsudans Zucc. & Th & $\mathrm{BQ}$ & 1383 \\
\hline Passiflora jorullensis H.B.K. & Th & $\mathrm{BMM}$ & 1661,1706 \\
\hline $\begin{array}{l}\text { "Passiflora macvaughiana J.M. MacDougal } \\
\text { PHYTOLACCACEAE (1/1) }\end{array}$ & Th & BMM & 2296 \\
\hline $\begin{array}{l}\text { Phytolacca icosandra } \mathrm{L} . \\
\text { PIPERACEAE }(2 / 11)\end{array}$ & $\mathrm{H}$ & BTS & 1754 \\
\hline${ }^{*}$ Peperomia aff. collocata Trel. & $\mathrm{H}$ & $\mathrm{BMM}$ & 1700 \\
\hline${ }^{*}$ Peperomia cordovana C. DC. & $\mathrm{H}$ & BMM & 1303 \\
\hline *Peperomia galioides Kunth & $\mathrm{He}$ & BMM & 1575 \\
\hline *Peperomia hoffmannii C. DC. & $\mathrm{He}$ & BMM & 1690 \\
\hline${ }^{*}$ Peperomia mexicana (Miq.) Miq. & $\mathrm{Hr}$ & BTS & 2036 \\
\hline Peperomia molithrix Trel. \& Standl. & $\mathrm{Hr}$ & ECT & 1488 \\
\hline Peperomia sp. 1 & $\mathrm{He}$ & BQ & 2057 \\
\hline Peperomia sp. 2 & $\mathrm{He}, \mathrm{Hr}$ & ECT & 1846 \\
\hline Piper rosei C. DC. & $\mathrm{a}, \mathrm{A}$ & ECT & 1489 \\
\hline${ }^{*}$ Piper umbellatum $\mathrm{L}$. & $\mathrm{a}$ & ECT & 1491 \\
\hline $\begin{array}{l}\text { Piper villiramulum C. DC. } \\
\text { POLEMONIACEAE }(2 / 4)\end{array}$ & A & ECT & 1490 \\
\hline Bonplandia geminiflora Cav. & $\mathrm{H}$ & VS & 1786 \\
\hline *Loeselia involucrata G. Don & $\mathrm{H}$ & VS & 1782 \\
\hline Loeselia mexicana (Lam.) Brandegee & $\mathrm{Sa}$ & BQ & 1944 \\
\hline $\begin{array}{l}\text { Loeselia sp. } \\
\text { POLYGALACEAE }(2 / 4)\end{array}$ & $\mathrm{H}$ & ECT & 1851 \\
\hline *Monnina xalapensis H.B.K. & $\mathrm{a}$ & BQ & 1917 \\
\hline
\end{tabular}


Apéndice. Continuación.

\begin{tabular}{|c|c|c|c|}
\hline TAXON & FV & TV & $\begin{array}{l}\text { Núm. de } \\
\text { colecta }\end{array}$ \\
\hline${ }^{*}$ Polygala gracillima $\mathrm{S}$. Watson & $\mathrm{H}$ & BQ & 1450 \\
\hline Polygala sp. 1 & $\mathrm{a}$ & BMM & 1608 \\
\hline Polygala sp. 2 & $\mathrm{H}$ & VS & 2074 \\
\hline POLYGONACEAE (1/1) & & & \\
\hline $\begin{array}{l}\text { Coccoloba barbadensis Jacq. } \\
\text { RANUNCULACEAE (3/4) }\end{array}$ & A & BTS & 1753 \\
\hline${ }^{*}$ Clematis acapulcensis Hook. \& Arn. & $\mathrm{Tl}$ & $\mathrm{BQ}$ & 2089 \\
\hline Clematis rhodocarpa Rose & $\mathrm{Tl}$ & $B Q, V S$ & 1557,1820 \\
\hline${ }^{*}$ Ranunculus petiolaris H.B.K. ex DC. var. petiolaris & $\mathrm{H}$ & $\mathrm{BMM}, \mathrm{BQ}$ & 1347,1434 \\
\hline $\begin{array}{l}{ }^{*} \text { Thalictrum pringlei } \mathrm{S} \text {. Watson } \\
\text { RHAMNACEAE }(3 / 4)\end{array}$ & $\mathrm{H}$ & BQ & 2062 \\
\hline Colubrina sp. & $\mathrm{a}, \mathrm{A}$ & BMM & 1619 \\
\hline Gouania lupuloides (L.) Urb. & $\mathrm{Tl}$ & VS & 2543 \\
\hline Rhamnus hintonii M.C. Johnst. \& L.A. Johnst. & A & BMM & 1457 \\
\hline $\begin{array}{l}\text { "Rhamnus sharpii M.C. Johnst. \& L.A. Johnst. } \\
\text { ROSACEAE (1/2) }\end{array}$ & A & $\mathrm{BMM}$ & 1635 \\
\hline Prunus brachybotrya Zucc. & A & BMM, ECT & $\begin{array}{l}1625,1715 \\
2041,2087\end{array}$ \\
\hline $\begin{array}{l}\text { Prunus cortapico Kerber ex Koehne } \\
\text { RUBIACEAE }(14 / 25)\end{array}$ & A & BMM, BTS & 1810,2038 \\
\hline "Borreria ocymoides (Burm. f.) DC. & $\mathrm{H}$ & BTS & 1474 \\
\hline${ }^{*}$ Bouvardia capitata Bullock Pr & $\mathrm{Sa}$ & BMM & 1616 \\
\hline${ }^{*}$ Bouvardia loeseneriana Standl. ${ }^{P r}$ & $\mathrm{a}$ & BMM & 1356 \\
\hline "Bouvardia standleyana W.H. Blackw. & $\mathrm{a}$ & BMM & 1587 \\
\hline Chiococca alba (L.) Hitchc. & $\mathrm{a}, \mathrm{A}$ & ECT & 1597 \\
\hline Chiococca pachyphylla Wernham & $\mathrm{a}, \mathrm{A}$ & BMM & 1937 \\
\hline "Arachnothryx jurgensenii (Hemsl.) Borhidi & $\mathrm{a}, \mathrm{A}$ & BMM, BTS & 1453,2067 \\
\hline Arachnothryx leucophylla (H.B.K.) Planch. & A & ECT & 1728 \\
\hline Arachnothryx manantlanensis (Lorence) Borhidi & $\mathrm{a}, \mathrm{A}$ & BMM & 1696 \\
\hline Borreria remota (Lam.) Bacigalupo \& Cabral & $\mathrm{H}$ & BMM & 1292 \\
\hline${ }^{*}$ Crusea calocephala DC. & $\mathrm{H}$ & $\mathrm{BP}$ & 1498 \\
\hline${ }^{*}$ Crusea coccinea DC. var. coccinea & $\mathrm{H}$ & BMM & 1291 \\
\hline $\begin{array}{l}\text { Crusea longiflora (Willd. ex Roem. \& Schult.) } \\
\text { W.R. Anderson }\end{array}$ & $\mathrm{H}$ & BMM, BQ & $\begin{array}{l}1299,1409 \\
1426\end{array}$ \\
\hline
\end{tabular}


Apéndice. Continuación.

\begin{tabular}{|c|c|c|c|}
\hline TAXON & $\mathrm{FV}$ & TV & $\begin{array}{l}\text { Núm. de } \\
\text { colecta }\end{array}$ \\
\hline 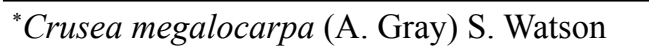 & $\mathrm{H}$ & BMM & 1309 \\
\hline Crusea parviflora Hook. \& Arn. & $\mathrm{H}$ & BQ & 1926 \\
\hline Galium mexicanum H.B.K. & Th & BQ & 1432 \\
\hline "Gonzalagunia panamensis (Cav.) K. Schum. & $\mathrm{a}$ & BTS & 1461 \\
\hline Hamelia xorullensis H.B.K. & A & VS & 1556 \\
\hline Hoffmannia cuneatissima B.L. Rob. & $\mathrm{Sa}$ & $\mathrm{BMM}$ & 1807 \\
\hline Psychotria horizontalis Sw. & $\mathrm{a}, \mathrm{A}$ & BMM & 116 \\
\hline${ }^{*}$ Psychotria pubescens $\mathrm{Sw}$. & $\mathrm{a}$ & BTS & 1644 \\
\hline Randia aculeata $\mathrm{L}$. & $\mathrm{A}$ & VS & 1877 \\
\hline Randia capitata DC. & $\mathrm{A}$ & $\mathrm{BMM}$ & 1863 \\
\hline${ }^{*}$ Rogiera amoena Planch. & $\mathrm{a}, \mathrm{A}$ & BTS, ECT & 1651,1837 \\
\hline $\begin{array}{l}\text { Sommera grandis (Bartling ex DC.) Standl. } \\
\text { RUTACEAE }(2 / 3)\end{array}$ & A & BTS & 1652 \\
\hline "Amyris mexicana Lundell & $\mathrm{A}$ & BMM & 1939 \\
\hline${ }^{*}$ Amyris rekoi S.F. Blake & A & BMM & 1869 \\
\hline $\begin{array}{l}\text { Zanthoxylum mollissimum (Engl.) P. Wilson } \\
\text { SABIACEAE }(1 / 1)\end{array}$ & A & VS & 1552 \\
\hline $\begin{array}{l}\text { Meliosma nesites I.M. Johnst. } \\
\text { SALICACEAE (1/1) }\end{array}$ & A & BQ & 104 \\
\hline $\begin{array}{l}\text { Salix bonplandiana } \text { H.B.K. } \\
\text { SAPINDACEAE }(4 / 7)\end{array}$ & A & BTS & 2009 \\
\hline Cupania dentata $\mathrm{DC}$. & $\mathrm{A}$ & VS & 1889 \\
\hline${ }^{*}$ Cupania aff. scrobiculata Rich. & A & ECT & 1960 \\
\hline${ }^{*}$ Paullinia costaricensis Radlk. & $\mathrm{Tl}$ & ECT & 1848 \\
\hline Paullinia sessiliflora Radlk. & $\mathrm{Tl}$ & ECT & 1831 \\
\hline${ }^{*}$ Serjania flaviflora Radlk. & $\mathrm{Tl}$ & BQ & 1988 \\
\hline Serjania $\mathrm{sp.}$ & $\mathrm{Tl}$ & $\mathrm{BMM}$ & 1987 \\
\hline $\begin{array}{l}\text { Thouinidium decandrum (H.B.K.) Radlk. } \\
\text { SAPOTACEAE (1/1) }\end{array}$ & A & BTS & 2008 \\
\hline $\begin{array}{l}\text { *Sideroxylon aff. salicifolium (L.) Lam. } \\
\text { SCROPHULARIACEAE (8/11) }\end{array}$ & A & $\mathrm{BMM}$ & 1621 \\
\hline Buchnera pusilla H.B.K. & $\mathrm{H}$ & BQ & 1521,1676 \\
\hline${ }^{*}$ Calceolaria sp. & $\mathrm{H}$ & BMM & 1354 \\
\hline${ }^{*}$ Castilleja arvensis Cham. \& Schltdl. & $\mathrm{H}$ & BTS & 1907 \\
\hline
\end{tabular}


Apéndice. Continuación.

\begin{tabular}{|c|c|c|c|}
\hline TAXON & FV & TV & $\begin{array}{l}\text { Núm. de } \\
\text { colecta }\end{array}$ \\
\hline${ }^{*}$ Castilleja gracilis Benth. & $\mathrm{H}$ & BQ & 1392 \\
\hline Castilleja tenuiflora Benth. & $\mathrm{Sa}$ & ECT & 2088 \\
\hline${ }^{*}$ Lamourouxia multifida H.B.K. & $\mathrm{H}$ & BMM, BQ & 1713,1745 \\
\hline Lamourouxia viscosa H.B.K. & $\mathrm{H}$ & $\mathrm{BQ}, \mathrm{BP}$ & 1678,1824 \\
\hline${ }^{2}$ Penstemon roseus (Sweet) G. Don & $\mathrm{H}$ & $\mathrm{BQ}$ & 1520 \\
\hline${ }^{*}$ Russelia retrorsa Greene & $\mathrm{a}$ & BQ & 1524 \\
\hline Scoparia dulcis $\mathrm{L}$. & $\mathrm{H}$ & VS & 1888 \\
\hline $\begin{array}{l}{ }^{*} \text { Stemodia macrantha B.L. Rob. } \\
\text { SIMAROUBACEAE }(1 / 1)\end{array}$ & $\mathrm{H}$ & $\mathrm{ECT}$ & 1854 \\
\hline $\begin{array}{l}\text { Picramnia guerrerensis W.W. Thomas } \\
\text { SOLANACEAE }(6 / 16)\end{array}$ & $\mathrm{a}, \mathrm{A}$ & BTS & 1464 \\
\hline Cestrum nitidum M. Martens \& Galeotti & $\mathrm{a}, \mathrm{A}$ & BMM & 1634,1873 \\
\hline${ }^{*}$ Cestrum tomentosum $\mathrm{L}$. $\mathrm{f}$. & $\mathrm{A}$ & VS & 1879 \\
\hline Jaltomata procumbens (Cav.) J.L. Gentry & $\mathrm{H}$ & BMM & 1371 \\
\hline $\begin{array}{l}\text { "Lycianthes manantlanensis Aarón Rodr. \& O. } \\
\text { Vargas }\end{array}$ & $\mathrm{a}, \mathrm{A}$ & BMM, BTS & 1658,1699 \\
\hline${ }^{*}$ Lycianthes surotatensis Gentry & $\mathrm{Sa}$ & BTS, ECT & 1479,1898 \\
\hline Lycianthes sp. & $\mathrm{H}$ & ECT & 1802 \\
\hline${ }^{*}$ Physalis chenopodifolia Lam. & $\mathrm{H}$ & BMM & 1534 \\
\hline Physalis gracilis Miers & $\mathrm{H}$ & BTS & 1794 \\
\hline "Solandra nitida Zuccagni & $\mathrm{Tl}$ & $\mathrm{BMM}$ & 1622 \\
\hline Solanum brevipedicellatum K.E. Roe & A & BMM & 1856 \\
\hline Solanum candidum Lindl. & $\mathrm{a}$ & BTS & 1460 \\
\hline Solanum ferrugineum Jacq. & $\mathrm{a}$ & $\mathrm{BQ}$ & 1440 \\
\hline "Solanum lanceifolium Jacq. & $\mathrm{a}, \mathrm{Tl}$ & BTS, ECT & $\begin{array}{l}1375,2039 \\
2042\end{array}$ \\
\hline "Solanum nigrescens $\mathrm{M}$. Martens \& Galeotti & $\mathrm{H}$ & BQ & 1421 \\
\hline Solanum refractum Hook. \& Arn. & $\mathrm{Tl}$ & VS & 2033 \\
\hline $\begin{array}{l}\text { "Solanum verrucosum Schltdl. } \\
\text { STAPHYLEACEAE }(1 / 1)\end{array}$ & $\mathrm{H}$ & BQ & 2051 \\
\hline $\begin{array}{l}{ }^{*} \text { Turpinia occidentalis (Sw.) G. Don } \\
\text { STERCULIACEAE }(4 / 5)\end{array}$ & $\mathrm{A}$ & BMM & 1618 \\
\hline Ayenia abutilifolia (Turcz.) Turcz. & $\mathrm{Sa}$ & VS & 1791 \\
\hline
\end{tabular}


Apéndice. Continuación.

\begin{tabular}{|c|c|c|c|}
\hline TAXON & $\mathrm{FV}$ & $\mathrm{TV}$ & $\begin{array}{l}\text { Núm. de } \\
\text { colecta }\end{array}$ \\
\hline Guazuma ulmifolia Lam. & A & VS & 2297 \\
\hline Melochia nodiflora Sw. & $\mathrm{H}$ & VS & 1773 \\
\hline Melochia pyramidata $\mathrm{L}$. & $\mathrm{H}$ & VS & 1781 \\
\hline $\begin{array}{l}\text { Physodium adenodes (Goldberg) Fryxell var. } \\
\text { adenodes }\end{array}$ & A & VS & 1880 \\
\hline STYRACACEAE $(1 / 1)$ & & & \\
\hline $\begin{array}{l}\text { Styrax ramirezii Greenm. } \\
\text { SYMPLOCACEAE (1/1) }\end{array}$ & $\mathrm{A}$ & ECT & 1803 \\
\hline $\begin{array}{l}\text { *Symplocos novogaliciana L.M. González } \\
\text { THEACEAE }(2 / 2)\end{array}$ & A & $\mathrm{BMM}$ & 1610,1990 \\
\hline Symplococarpon purpusii (Brandegee) Kobuski & A & BMM & 1627 \\
\hline $\begin{array}{l}\text { Ternstroemia lineata DC. } \\
\text { TILIACEAE }(3 / 3)\end{array}$ & A & BQ & 1398,1740 \\
\hline *Corchorus hirsutus L. & $\mathrm{Sa}$ & VS & 1561 \\
\hline *Heliocarpus aff. americanus L. & A & BMM & 1707 \\
\hline $\begin{array}{l}\text { Triumfetta galeottiana Turcz. } \\
\text { ULMACEAE }(2 / 2)\end{array}$ & $\mathrm{a}$ & ECT & 1591 \\
\hline Aphananthe monoica (Hemsl.) J.-F. Leroy & A & BTS & 1901 \\
\hline $\begin{array}{l}\text { Trema micrantha }(\mathrm{L} .) \text { Blume } \\
\text { URTICACEAE }(5 / 7)\end{array}$ & A & BMM & 1985 \\
\hline *Boehmeria corallina Wedd. & A & $\mathrm{BMM}$ & 1585 \\
\hline Boehmeria ulmifolia Wedd. & a & BMM, BTS & 1617,1643 \\
\hline${ }^{*}$ Gyrotaenia $\mathrm{sp}$. & A & BTS & 2035 \\
\hline Phenax mexicanus Wedd. & A & BMM & 1666 \\
\hline Pilea hyalina Fenzl & $\mathrm{H}$ & BTS & 1475 \\
\hline Pilea sp. & $\mathrm{H}$ & BMM & 1350 \\
\hline $\begin{array}{l}\text { Urera corallina }(\text { Liebm.) Wedd. } \\
\text { VALERIANACEAE }(1 / 3)\end{array}$ & $\mathrm{a}, \mathrm{A}$ & BTS & 2037,2040 \\
\hline *Valeriana robertianifolia Briq. & $\mathrm{H}$ & $\mathrm{BQ}$ & 1395 \\
\hline Valeriana sorbifolia H.B.K. & $\mathrm{H}$ & BMM & 1584 \\
\hline $\begin{array}{l}\text { Valeriana urticifolia } \text { H.B.K. } \\
\text { VERBENACEAE }(4 / 5)\end{array}$ & $\mathrm{H}$ & BMM, BQ & 1332,2061 \\
\hline Citharexylum aff. glabrum (S. Watson) Greenm. & A & BMM & 1859,1952 \\
\hline
\end{tabular}


Apéndice. Continuación.

\begin{tabular}{llll}
\hline TAXON & FV & TV & $\begin{array}{l}\text { Núm. de } \\
\text { colecta }\end{array}$ \\
\hline $\begin{array}{l}\text { Citharexylum hexangulare Greenm. } \\
\text { "Lantana frutilla Moldenke }\end{array}$ & A & BMM & 1860 \\
$\begin{array}{l}\text { Lippia umbellata } \text { Cav. } \\
\text { Priva aspera } \text { H.B.K. }\end{array}$ & a & BTS, VS & 1372,2030 \\
VIOLACEAE (1/1) & H & BQ & 1946 \\
${ }^{*}$ Hybanthus elatus (Turcz.) C.V. Morton & & & 1429 \\
VISCACEAE (1/2) & a & BMM & 1348 \\
${ }^{*}$ Phoradendron longifolium Eichler ex Trel. & & & \\
Phoradendron wattii Trel. & ah-p & BMM & 1637 \\
VITACEAE (1/1) & ah-p & VS & 1563 \\
Vitis blancoi Munson & & & \\
& Tl & BMM, BTS & 1752,1717
\end{tabular}

\section{LILIOPSIDA}

AGAVACEAE (3/3)

"Agave vasquezgarciae Cházaro \& Lomelí-Sención

Furcraea aff. guerrerensis Matuda

$\mathrm{H} \quad \mathrm{BQ}$

1933,1943

*Manfreda scabra (Ortega) McVaugh

$\mathrm{H} \quad \mathrm{BMM}$

2021

ARACEAE (3/3)

Anthurium halmoorei Croat

$\mathrm{H} \quad \mathrm{BQ}$

1435

"Philodendron anisotomum Schott

$\mathrm{Hr} \quad \mathrm{ECT}$

1832

Xanthosoma hoffmannii (Schott) Schott

Tl BTS

ARECACEAE (1/1)

Chamaedorea pochutlensis Liebm. ${ }^{\mathbf{A}}$

$\mathrm{H}$

BTS

1750

BROMELIACEAE (3/9)

Bromelia plumieri (E. Morr.) L.B. Sm.

BMM

1513

Pitcairnia heterophylla (Lindl.) Beer

$\mathrm{a}$

H BTS

"Pitcairnia karwinskyana Schult. f.

$\mathrm{He} \quad \mathrm{BMM}$

"Pitcairnia micheliana André

$\mathrm{Hr}$

BMM

1614

Tillandsia achyrostachys E. Morren ex Baker

$\mathrm{Hr} \quad \mathrm{ECT}$

1654

${ }^{*}$ Tillandsia calothyrsus Mez

$\mathrm{H}$

$\mathrm{H}$

"Tillandsia cossonii Baker

$\mathrm{H}$

Tillandsia dasyliriifolia Baker

$\mathrm{He} \quad \mathrm{BQ}$

2016

Tillandsia usneoides (L.) L.

$\mathrm{He} \quad \mathrm{BQ}$ 
Apéndice. Continuación.

\begin{tabular}{|c|c|c|c|}
\hline TAXON & FV & TV & $\begin{array}{l}\text { Núm. de } \\
\text { colecta }\end{array}$ \\
\hline \multicolumn{4}{|l|}{ COMMELINACEAE $(5 / 13)$} \\
\hline${ }^{*}$ Commelina dianthifolia Delile & $\mathrm{H}$ & $\mathrm{BP}$ & $1503 \mathrm{a}$ \\
\hline Commelina diffusa Burm. f. & $\mathrm{H}$ & BTS & 1470 \\
\hline Commelina erecta $\mathrm{L}$. & $\mathrm{H}$ & BQ & 1441 \\
\hline Commelina leiocarpa Benth. & $\mathrm{H}$ & BQ & 1742 \\
\hline Commelina tuberosa $\mathrm{L}$. & $\mathrm{H}$ & $\mathrm{BMM}, \mathrm{BP}$ & $1312,1503 \mathrm{~b}$ \\
\hline $\begin{array}{l}\text { Gibasis pellucida (M. Martens \& Galeotti) D.R. } \\
\text { Hunt }\end{array}$ & $\mathrm{H}$ & BMM & 1302 \\
\hline${ }^{*}$ Gibasis triflora (M. Martens \& Galeotti) D.R. Hunt & $\mathrm{H}$ & $\mathrm{BQ}$ & 1422 \\
\hline Tinantia erecta (Jacq.) Schltdl. & $\mathrm{H}$ & BMM & $1535 \mathrm{~b}$ \\
\hline Tinantia parviflora Rohweder & $\mathrm{H}$ & VS & 1558 \\
\hline Tinantia standleyi Steyerm. & $\mathrm{H}$ & BMM & $1535 \mathrm{a}$ \\
\hline *Tradescantia commelinoides Schult. f. & $\mathrm{H}$ & BMM & 1304 \\
\hline *Tradescantia zanonia (L.) Sw. & $\mathrm{H}$ & BTS & 1647 \\
\hline $\begin{array}{l}\text { Tripogandra amplexicaulis (Klotzsch ex C.B. } \\
\text { Clarke) Woodson }\end{array}$ & $\mathrm{H}$ & BQ & 1469,1532 \\
\hline \multicolumn{4}{|l|}{ CYPERACEAE (6/12) } \\
\hline Bulbostylis juncoides (Vahl) G. Kük. ex Osten & $\mathrm{H}$ & BQ & 1408 \\
\hline *Bulbostylis tenuifolia (Rudge) J.F. Macbr. & $\mathrm{H}$ & BQ & 1406 \\
\hline Carex sp. & $\mathrm{H}$ & BMM & 1456 \\
\hline Cyperus flavescens L. var. piceus (Liebm.) Fernald & $\mathrm{H}$ & BTS & 1471 \\
\hline Cyperus hermaphroditus (Jacq.) Standl. & $\mathrm{H}$ & BMM, BQ & 1308,1427 \\
\hline Cyperus nayaritensis G.C. Tucker & $\mathrm{H}$ & BQ & 1386 \\
\hline Cyperus spectabilis Link & $\mathrm{H}$ & BQ & 1436 \\
\hline Cyperus sp. & $\mathrm{H}$ & BMM & 1364 \\
\hline Kyllinga odorata Vahl & $\mathrm{H}$ & BQ & 1454 \\
\hline Kyllinga pumila Michx. & $\mathrm{H}$ & BTS & 1472 \\
\hline *Rhynchospora aristata Boeck. & $\mathrm{Hr}$ & BMM & 1340 \\
\hline Scleria sp. & $\mathrm{Hr}$ & BQ & 1407 \\
\hline \multicolumn{4}{|l|}{ DIOSCOREACEAE (1/4) } \\
\hline Dioscorea jaliscana $\mathrm{S}$. Watson & $\mathrm{Th}$ & BQ & 1480 \\
\hline Dioscorea militaris B.L. Rob. & Th & BQ & 1405 \\
\hline Dioscorea plumifera B.L. Rob. & Th & BMM & 1571 \\
\hline
\end{tabular}


Apéndice. Continuación.

\begin{tabular}{|c|c|c|c|}
\hline TAXON & FV & TV & $\begin{array}{l}\text { Núm. de } \\
\text { colecta }\end{array}$ \\
\hline $\begin{array}{l}\text { Dioscorea remotiflora Kunth } \\
\text { IRIDACEAE }(1 / 2)\end{array}$ & $\mathrm{Th}$ & BMM & 1659 \\
\hline "Tigridia ehrenbergii (Schltdl.) Molseed & $\mathrm{H}$ & $\mathrm{BMM}$ & 1574 \\
\hline $\begin{array}{l}\text { Tigridia meleagris (Lindl.) G. Nicholson } \\
\text { LILIACEAE }(5 / 5)\end{array}$ & $\mathrm{H}$ & $\mathrm{ECT}$ & 2084 \\
\hline Bessera elegans Schult. f. & $\mathrm{H}$ & BMM & 1328 \\
\hline Bomarea hirtella (H.B.K.) Herb. & $\mathrm{Th}$ & BMM & 1310 \\
\hline${ }^{*}$ Calochortus barbatus (H.B.K.) J.H. Painter & $\mathrm{Hr}$ & BQ & 1519 \\
\hline *Hymenocallis azteciana Traub & $\mathrm{H}$ & BQ & 2050 \\
\hline $\begin{array}{l}{ }^{*} \text { Hypoxis mexicana } \text { Schult. f. } \\
\text { ORCHIDACEAE }(12 / 18)\end{array}$ & $\mathrm{H}$ & BQ & 1420 \\
\hline *Aulosepalum nelsonii (Greenm.) Garay & $\mathrm{Hr}$ & VS & 2005 \\
\hline *Bletia neglecta Sosa & $\mathrm{H}$ & $\mathrm{BP}$ & 1830 \\
\hline *Bletia purpurata A. Rich. \& Galeotti & $\mathrm{H}$ & $\mathrm{BMM}$ & 1343 \\
\hline${ }^{*}$ Cranichis sylvatica A. Rich. \& Galeotti & $\mathrm{H}$ & BTS & 2546 \\
\hline Encyclia adenocaula (La Llave \& Lex.) Schltr. ${ }^{\mathbf{A}}$ & $\mathrm{He}$ & BMM & 2023 \\
\hline${ }^{*}$ Encyclia spatella (Rchb. f.) Schltr. & $\mathrm{Hr}$ & BMM & 2022 \\
\hline "Epidendrum miserum Lindl. & $\mathrm{He}$ & BQ & 1545 \\
\hline${ }^{*}$ Erycina diaphana (Rchb. f.) Schltr. & $\mathrm{He}$ & BQ & 1819 \\
\hline *Habenaria jaliscana S. Watson & $\mathrm{Hr}$ & BQ & 1412 \\
\hline Habenaria novemfida Lindl. & $\mathrm{H}$ & BMM & 1355 \\
\hline $\begin{array}{l}\text { Isochilus bracteatus (La Llave \& Lex.) Salazar } \\
\text { \& Soto Arenas ex Espejo \& López-Ferrari }\end{array}$ & $\mathrm{He}$ & BMM & 2046 \\
\hline "Malaxis brachyrrhynchos (Rchb f.) Ames & $\mathrm{Hz}$ & BMM & $1349 \mathrm{~b}$ \\
\hline Malaxis rosilloi R. González \& E.W. Greenw. & $\mathrm{H}$ & BMM & 1349 a \\
\hline *Oncidium cebolleta (Jacq.) Sw. & $\mathrm{He}$ & VS & 2000 \\
\hline *Oncidium karwinskii (Lindl.) Lindl. & $\mathrm{He}$ & BTS & 1642 \\
\hline${ }^{*}$ Oncidium tigrinum Lex. ${ }^{\mathbf{A}}$ & $\mathrm{He}$ & $\mathrm{BQ}$ & 1631 \\
\hline $\begin{array}{l}\text { *Rossioglossum splendens (Rchb. f.) Garay \& G.C. } \\
\text { Kenn. }{ }^{A}\end{array}$ & $\mathrm{He}$ & BQ & 1538 \\
\hline $\begin{array}{l}\text { Stelis longispicata (L.O. Williams) Pridgeon \& } \\
\text { M.W. Chase }\end{array}$ & $\mathrm{He}$ & BMM & 1537 \\
\hline \multicolumn{4}{|l|}{ POACEAE $(19 / 34)$} \\
\hline Aegopogon tenellus (DC.) Trin. & $\mathrm{H}$ & BQ & 1385 \\
\hline
\end{tabular}


Apéndice. Continuación.

\begin{tabular}{|c|c|c|c|}
\hline TAXON & FV & $\mathrm{TV}$ & $\begin{array}{l}\text { Núm. de } \\
\text { colecta }\end{array}$ \\
\hline Axonopus compressus (Sw.) P. Beauv. & $\mathrm{H}$ & VS & 2079 \\
\hline "Axonopus mexicanus G.A. Black & $\mathrm{H}$ & BQ & 1417 \\
\hline${ }^{*}$ Chusquea circinata Soderstr. \& C.E. Calderón & $\mathrm{a}$ & BTS & 2083 \\
\hline Digitaria ciliaris (Retz.) Koeler & $\mathrm{H}$ & BMM & 1366 \\
\hline Echinochloa colonum (L.) Link & $\mathrm{H}$ & VS & 2082 \\
\hline Eragrostis pectinacea (Michx.) Nees & $\mathrm{H}$ & VS & 2080 \\
\hline Lasiacis nigra Davidse & $\mathrm{a}$ & BTS & 1601,1603 \\
\hline Lasiacis procerrima (Hackel) Hitchc. & $\mathrm{H}$ & BQ & 1438 \\
\hline Lasiacis ruscifolia (H.B.K.) Hitchc. & $\mathrm{a}$ & VS & 1882 \\
\hline "Muhlenbergia ciliata (H.B.K.) Kunth & $\mathrm{H}$ & BTS & 2099 \\
\hline Muhlenbergia dumosa Scribn. ex Vasey & $\mathrm{H}$ & $\mathrm{BP}$ & 1829 \\
\hline "Muhlenbergia macrotis (Piper) Hitchc. & $\mathrm{H}$ & $\mathrm{BP}$ & 1507 \\
\hline Muhlenbergia tenella (H.B.K.) Trin. & $\mathrm{H}$ & $\mathrm{BQ}$ & 1630 \\
\hline${ }^{*}$ Muhlenbergia aff. tenuifolia (H.B.K.) Kunth & $\mathrm{H}$ & BQ & 1922 \\
\hline Oplismenus compositus (L.) P. Beauv. & $\mathrm{H}$ & $\mathrm{BMM}, \mathrm{BQ}$ & 1314,1400 \\
\hline $\begin{array}{l}\text { * Otatea acuminata (Munro) C.E. Calderón } \\
\text { \& Soderstr. }\end{array}$ & $\mathrm{a}$ & VS & 2011 \\
\hline "Panicum arundinariae Trin. ex E. Fourn. & $\mathrm{H}$ & BMM & 1640 \\
\hline "Panicum laxum Sw. & $\mathrm{H}$ & VS & 2081 \\
\hline Panicum maximum Jacq. & $\mathrm{H}$ & VS & 1550 \\
\hline Panicum trichoides Sw. & $\mathrm{H}$ & BTS & 1674 \\
\hline Paspalum botterii (E. Fourn.) Chase & $\mathrm{H}$ & VS & 1555 \\
\hline Paspalum conjugatum P.J. Bergius & $\mathrm{H}$ & BQ & 1483 \\
\hline Paspalum convexum Humb. \& Bonpl. & $\mathrm{H}$ & BQ & 1455 \\
\hline Paspalum lentiginosum J. Presl & $\mathrm{H}$ & VS & 2078 \\
\hline Paspalum squamulatum E. Fourn. & $\mathrm{H}$ & ECT & 1486 \\
\hline Pereilema ciliatum E. Fourn. & $\mathrm{H}$ & ECT & 1730 \\
\hline *Schizachyrium tenerum Nees & $\mathrm{H}$ & $\mathrm{BP}$ & 1494 \\
\hline Setaria parviflora (Poir.) Kerguélen & $\mathrm{H}$ & BMM & 1662 \\
\hline Sporobolus indicus (L.) R. Br. & $\mathrm{H}$ & BQ & 1418 \\
\hline Trachypogon secundus (J. Presl) Scribn. & $\mathrm{H}$ & BQ & 1404 \\
\hline Tripsacum dactyloides (L.) L. & $\mathrm{H}$ & BMM & 1636 \\
\hline $\begin{array}{l}\text { Zeugites americana Willd. var. mexicana (Kunth) } \\
\text { McVaugh }\end{array}$ & $\mathrm{H}$ & $\mathrm{BP}$ & 1506 \\
\hline
\end{tabular}


Acta Botanica Mexicana 84: 25-72 (2008)

Apéndice. Continuación.

\begin{tabular}{llll}
\hline TAXON & FV & TV & $\begin{array}{l}\text { Núm. de } \\
\text { colecta }\end{array}$ \\
\hline${ }^{*}$ Zeugites smilacifolia Scribn. & H & BMM & 1705 \\
SMILACACEAE $(1 / 2)$ & & & \\
Smilax moranensis M. Martens \& Galeotti & Tl & BMM, BTS & 1612,2064 \\
${ }^{*}$ Smilax ornata Lem. & Tl & BMM & 1579 \\
\hline
\end{tabular}

